\title{
ipen
}

INSTITUTO DE PESQUISAS ENERGÉTICAS E NUCLEARES AUTARQUIA ASSOCIADA À UNIVERSIDADE DE SÃO PAULO

\section{A INFLUÊNCIA DE REDES SOCIAIS NA CULTURA DE SEGURANÇA}

CARLOS HENRIQUE VERÍSSIMO PEREIRA

Dissertação apresentada ao Instituto de Pesquisas Energéticas e Nucleares como parte dos requisitos para obtenção do Grau de Mestre em Ciências na área de Tecnologia Nuclear - Aplicações.

Orientador:

Dr. Antônio Carlos de Oliveira Barroso

São Paulo 2011 


\section{ipen}

INSTITUTO DE PESQUISAS ENERGÉTICAS E NUCLEARES AUTARQUIA ASSOCIADA À UNIVERSIDADE DE SÃO PAULO

\section{A INFLUÊNCIA DE REDES SOCIAIS NA CULTURA DE SEGURANÇA}

CARLOS HENRIQUE VERÍSSIMO PEREIRA

Dissertação apresentada ao Instituto de Pesquisas Energéticas e Nucleares como parte dos requisitos para obtenção do Grau de Mestre em Ciências na área de Tecnologia Nuclear - Aplicações.

Orientador:

Dr. Antônio Carlos de Oliveira Barroso

São Paulo 2011 


\section{Dedicatória}

Dedico este trabalho à DEUS, por me proporcionar esta oportunidade grandiosa, à minha esposa, Valquíria, e ao meu filho, Fernando Henrique, pela compreensão de minha ausência para dedicar-me a este trabalho e ao meu grande amigo e irmão Roberto Correia de Melo, por acreditar em meu potencial. 


\section{Agradecimentos}

Concluo esta jornada com sentimento de dever cumprido, ao deixar um legado à sociedade e, também sinto-me realizado pelo cabedal de conhecimento adquirido no transcorrer deste trabalho, proporcionado por pessoas com desprendimento e de elevado espírito de colaboração, aos quais sou imensamente grato.

Agradeço;

Ao Prof. Dr. Antônio Carlos de Oliveira Barroso, que transcende ao grandioso papel de orientar e, com simplicidade e paciência, características de um sábio, me conduziu nesta árdua e gratificante tarefa.

Sou muitíssimo grato à:

Ana Maria Maiorino pela valorosa e salvadora assistência;

Antônio Souza Vieira Neto, pelas incontáveis assistências, em conteúdo teórico e conhecimento em cultura de segurança;

Calil Mohamed Farra Filho, pela amizade neste período de convivência no IPEN;

Carlos Anísio Monteiro, por me disponibilizar seu acervo bibliográfico;

Colegas do Grupo de Pesquisa - Gestão do Conhecimento que acompanharam a trajetória deste trabalho;

Funcionários dos vários Centros do IPEN, que com muita boa vontade e presteza, responderam aos questionários, parte essencial neste trabalho; 
Leila Modanez, pela inestimável ajuda nas disciplinas de Fundamentos de Reatores;

Pessoal do Ensino: Gislene Madeira, Rose, Vera Lúcia Mariano Garcia (Verinha), pela presteza no atendimento de minhas solicitações;

Prof. Dr. Kengo Imakuma, pelo compartilhamento de sua experiência;

Prof. Dr. Mário Olímpio de Menezes, pelas colaborações, por ocasião do seminário de área;

Professores que transmitiram conhecimento nas disciplinas cursadas no IPEN.

Rita Izabel Ricciardi, por me abrir muitas portas na fase de pesquisa de campo;

Todas as pessoas do meu convívio que, direta ou indiretamente, compartilharam de uma corrente positiva para a conclusão deste trabalho; e Ao IPEN por me proporcionar esta grande oportunidade de crescimento acadêmico e pessoal. 


\section{Epígrafe}

"Existe uma coisa que uma longa existência me ensinou: toda a nossa ciência, comparada à realidade, é primitiva e inocente; e, portanto, é o que temos de mais valioso."

Albert Einstein 


\title{
A Influência de redes Sociais na Cultura de Segurança
}

\author{
Carlos Henrique Veríssimo Pereira
}

RESUMO

Em um ambiente corporativo, depois de algum tempo, as pessoas sabem a quem recorrer quando necessitam de ajuda ou de algum conhecimento que não dispõem, caracterizando um contexto de múltiplas influências entre pessoas ou redes de relacionamentos. Desta forma, o trabalho proposto, teve como objetivo identificar os atores da rede de relacionamentos, que exercem maior influência no comportamento de segurança. Para isso, fomos buscar na literatura estudos de abordagens teóricas e práticas, que utilizassem conceitos sócio-antropológicos, de preferência trabalhos com enfoque na área nuclear, que possuíssem questionários de cultura de segurança, devidamente testados e avaliados por métodos estatísticos. Como resultado, identificamos inúmeros atributos que podem caracterizar uma cultura de segurança positiva e, extraímos quatro daqueles que mais apareciam nos diversos estudos. A partir daí, concebemos as questões que nos possibilitassem mapear e entender as redes sociais que influenciam sobre a formação e manutenção destas características. Então, aplicamos nossa pesquisa no âmbito do IPEN-CNEN-SP, no qual utilizamos a técnica de pesquisa tipo bola de neve para mapeamento das redes sociais de compartilhamento de idéias, bem como aplicamos também o questionário para mapear as crenças dos atores com significativo grau de influência (obtido a partir do levantamento de redes de influências). Embasado em técnicas de análise de redes sociais, obtivemos subsídios para comprovação de que as redes dos atores mais influentes são relevantes na formação de cultura de segurança do IPEN-CNEN-SP.

Palavras Chaves: Redes Sociais; Cultura de Segurança. 


\title{
The Influence of Social Networks in the Safety Culture
}

\author{
Carlos Henrique Veríssimo Pereira
}

\begin{abstract}
In a corporative environment, after a while, people know to whom to turn to when they require help or some knowledge non available at their disposal, characterizing a context of multiple influences among people or relationship network. This way, the proposed work had as objective to identify actors, from relationship network that exerts a higher influence in safety behavior. For this, we researched in the literature studies on theoretical and practical approaches, which would use social-anthropological concepts, especially works with approach in nuclear area, provided with questionnaires on safety culture, strictly tested and assessed via statistical methods. This resulted in the identification of a lot of attributes able to characterize a positive safety culture and from them extracting four of the most shown in various studies. From now on, there were conceived questions for making viable the mapping out and the understanding of social network responsible for influencing the building-up and the maintenance of these characteristics. So, it was applied in our research, within IPEN-CNEN-SP extent, the snowball type as research technique, for the mapping out of social network toward ideas sharing, as well it was applied the questionnaire intended for mapping out actors believes with a significant influence degree (obtained from influences network survey). Based in social network analyses techniques, we obtained subsides for proving that network from actors the most influent are relevant for the building-up of IPEN-CNEN-SP safety culture.
\end{abstract}

Key Words: Social Network; Safety Culture; 


\section{LISTA DE FIGURAS}

Figura 1 - Rede de influências de cultura de segurança dos funcionários do IPEN-CNEN-SP 51

Figura 2 - Significado da rede visão de segurança do ponto de vista do respondente. 55

Figura 3 - Significado da rede visão de segurança do ponto de vista do fluxo de influência. 56

Figura 4 - Rede Visão de Segurança Original 57

Figura 5 - Rede Visão de Segurança Reduzida. 58

Figura 6- Significado dos arcos na rede de abertura e comunicação 61

Figura 7 - Significado dos arcos da rede Trabalho em Equipe 64

Figura 8 - Rede de influências de cultura de segurança dos funcionários do IPEN-CNEN-SP - Aprendizagem Organizacional" 66

Figura 9 - Escore dos pesquisados, relativos ao vetor cultural 73

Figura 10 - Histograma da Distribuição de Quíntuplas e Posição da Quíntupla dos mais centrais 76 


\section{LISTA DE TABELAS}

TABELA 1 - DEFINIÇÕES DO TERMO “CULTURA DE SEGURANÇA” ENCONTRADAS

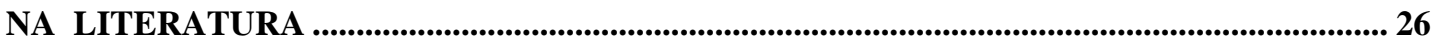

TABELA 2 - PRINCIPAIS PUBLICAÇÕES DA AIEA A RESPEITO DE CULTURA DE SEGURANÇA 30

TABELA 3 - SUMÁRIO DO PROCESSO DE LEVANTAMENTO DE REDES E CRENÇAS

TABELA 4 - COMPORTAMENTO DO VETOR CULTURAL DOS 45 FUNCIONÁRIOS QUE RESPONDERAM AO QUESTIONÁRIO DE CRENÇAS..................................................... 48

TABELA 5 - CARACTERÍSTICAS E INDICADORES DA REDE MULTIAGREGADA ..... 52

TABELA 6 - BASE PARA CONTAGEM DO RANKING DOS FUNCIONÁRIOS MAIS INFLUENTES NA REDE

TABELA 7 - RANKING DOS FUNCIONÁRIOS MAIS INFLUENTES NA REDE DE INFLUENCIA DE CULTURA DE SEGURANÇA..................................................................... 53

TABELA 8 - CARACTERÍSTICAS E INDICADORES DA REDE VISÃO DE SEGURANÇA

TABELA 9 - RANKING DOS FUNCIONÁRIOS MAIS INFLUENTES NA REDE VISÃO DE SEGURANÇA 60

TABELA 10 - CARACTERÍSTICAS E INDICADORES DA REDE ABERTURA E COMUNICAÇÃO 62

TABELA 11 - RANKING DOS FUNCIONÁRIOS MAIS INFLUENTES NA REDE ABERTURA E COMUNICAÇÃO 63

TABELA 12 - CARACTERÍSTICAS E INDICADORES DA REDE TRABALHO EM EQUIPE 
TABELA 13 - RANKING DOS FUNCIONÁRIOS MAIS INFLUENTES NA REDE TRABALHO EM EQUIPE.

TABELA 14 - CARACTERÍSTICAS E INDICADORES DA REDE APRENDIZAGEM

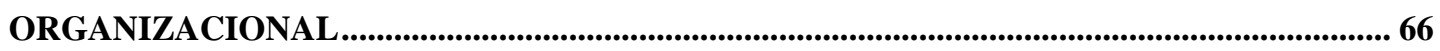

TABELA 15 - QUADRO RESUMO DAS REDES ........................................................................ 67

TABELA 16 - VETOR CULTURAL DAS REDES DE RELACIONAMENTOS DO IPENCNEN-SP 


\section{LISTA DE ABREVIATURAS E SIGLAS}

SIGLA

AIEA

ASCOT

CNEN

HSE

INSAG

IPEN

OCDE

SCART
SIGNIFICADO

Agência Internacional de Energia Atômica

Assessment of Safety Culture in Organizations Team

Comissão Nacional de Energia Nuclear

Health and Safety Executive

International Nuclear Safety Advisory Group

Instituto de Pesquisas Energéticas e Nucleares

Organização para a Cooperação e Desenvolvimento Econômico

Safety Culture Assessment Review Team 


\section{SUMÁRIO}

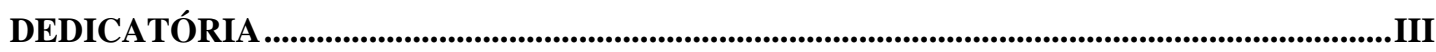

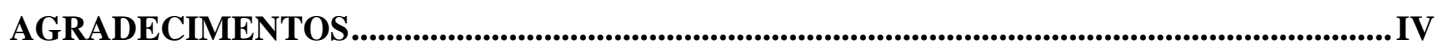

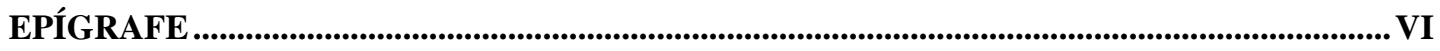

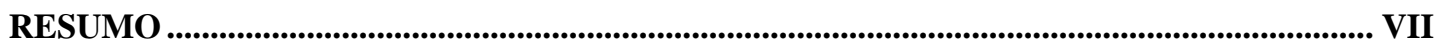

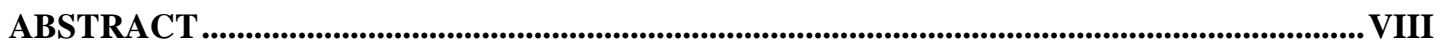

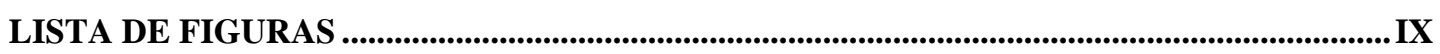

LISTA DE TABELAS......................................................................................................................... X

LISTA DE ABREVIATURAS E SIGLAS .............................................................................. XII

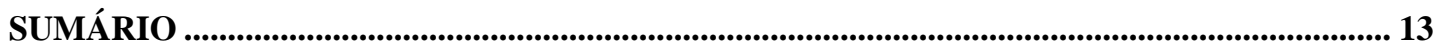

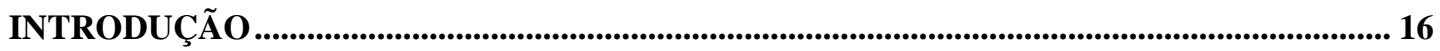

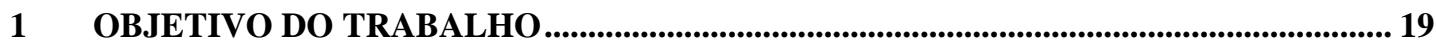

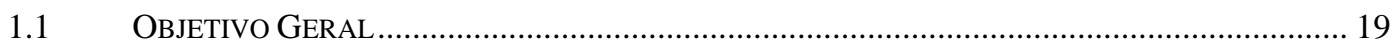

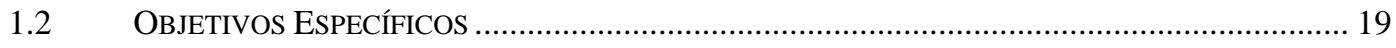

2 FUNDAMENTAÇÃO TEÓRICA.............................................................................................. 20

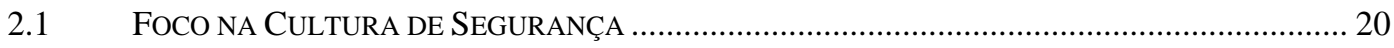

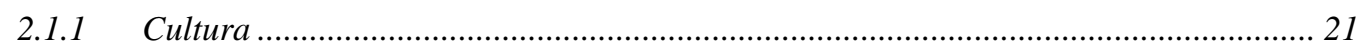

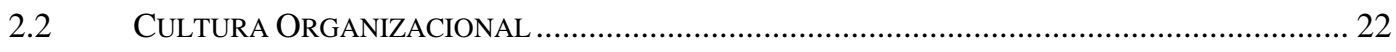

2.2.1 Definindo Cultura de Segurança ......................................................................... 24

2.2.1.1 A cronologia do termo "Cultura de Segurança”"............................................................... 24

2.2.1.2 A cultura de segurança pela Agência Internacional de Energia Atômica......................... 28

2.3 A MEMÉTICA E A REPLICAÇÃO DA CULTURA …........................................................... 30

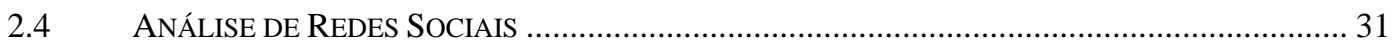

2.4.1 Indicadores de Análise de Redes Sociais Utilizados .................................................. 32

2.4.1.1 Métricas para avaliar a rede como um todo : .................................................................... 34

2.4.1.2 Métricas para avaliar influências dos atores na rede ......................................................... 35 


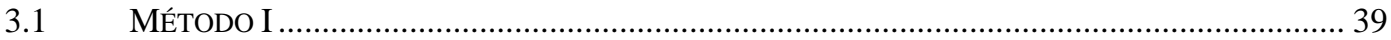

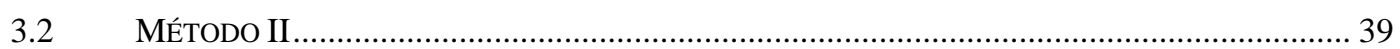

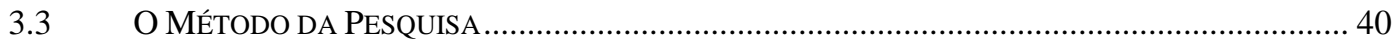

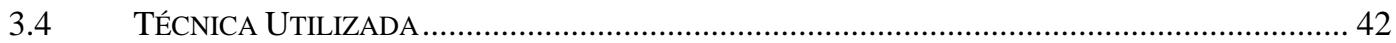

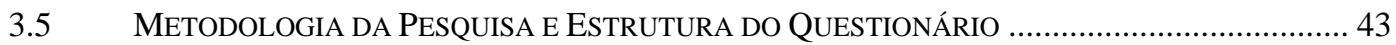

3.5.1 A Pesquisa Semente.............................................................................................. 43

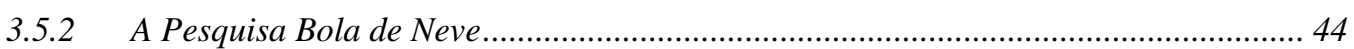

3.5.3 Aplicação do Questionário de Crenças - Aspectos de Segurança ................................... 44

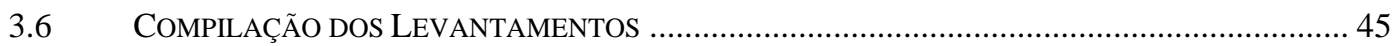

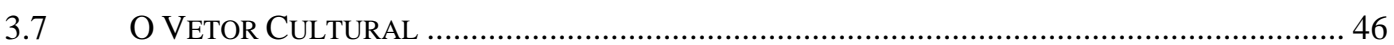

$4 \quad$ RESULTADOS - ANÁLISE DAS REDES ...................................................................50

4.1 A CONFORMAÇ̃̃o DAS REDES ESTUDADAS ................................................................... 50

4.2 Rede Agregada (MultiRede Agregada) ................................................................ 51

4.3 Base Para ANÁlise dos Atores Mais InfLUENTES NA REDE DE INFLUÊNCIAS............... 52

4.4 FUNCIONÁRIOS MAIS INFLUENTES............................................................................... 53

4.5 ANALISANDO RESULTADOS DE CADA REDE ……........................................................... 54

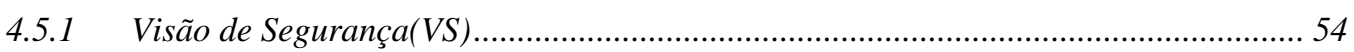

4.5.1.1 Análise da rede VS como um todo.............................................................................. 57

4.5.1.2 Funcionários mais influentes da rede Visão de Segurança ................................................ 59

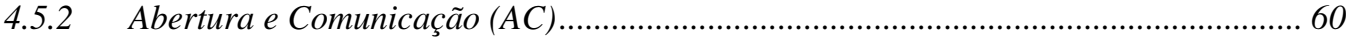

4.5.2.1 Funcionários mais influentes da rede Abertura e Comunicação .......................................... 62

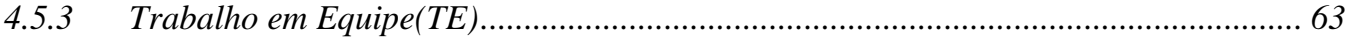

4.5.3.1 Funcionários mais influentes da rede Trabalho em Equipe................................................ 65

4.5.4 Rede Aprendizagem Organizacional(AO) ............................................................... 65

4.5.5 Resumo Conclusivo da Análise das Redes .................................................................. 67

4.5.6 Análise de Caracterização da Cultura de Segurança ................................................ 70

4.5.7 Análise Cruzada da Caracterização da Cultura de Segurança Com as Redes de

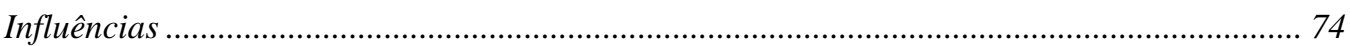

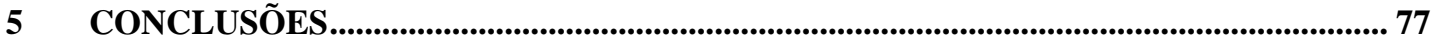

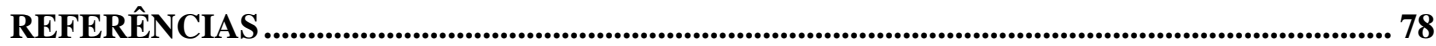

ANEXO A - MODELO DE CARTA ENVIADA AOS GERENTES ....................................... 81

ANEXO B - QUESTIONÁRIO PARA LEVANTAMENTO DAS REDES................................. 83 
ANEXO C - QUESTIONÁRIO PARA LEVANTAMENTO DAS CRENÇAS................................. 86 ANEXO D - FLUXO DO LEVANTAMENTO DE REDES ….....................................................90 


\section{INTRODUÇÃO}

O rápido desenvolvimento de novas tecnologias trouxe, fundamentalmente, mudanças na natureza do trabalho e o incremento de sistemas complexos às várias indústrias, Hendrick(1991).

Dentre estes sistemas complexos, Wiegmann et al. (2002) destacam que estes requerem um forte acoplamento entre os subsistemas técnico e humano. Exemplo disto são as usinas nucleares, instalações de processamento químico e operações de aviação civil. A falha de qualquer subsistema pode muitas vezes causar uma falha de todo o sistema. Além disso, falhas catastróficas desses sistemas de alto risco representam sérias ameaças, não só para aqueles dentro da organização, mas também para o público nele inserido. Para alguns sistemas potencialmente muito perigosos, como a energia nuclear, este risco pode se estender para além da localidade imediata. Segundo a ótica de James Reason:

“...não há nada de novo no que se refere a acidentes trágicos causados por erro humano. No passado, as consequências prejudiciais eram geralmente confinados à vizinhança imediata ao acidente. Agora, sendo a natureza e a dimensão de certas tecnologias potencialmente perigosas, especialmente as usinas nucleares, significam que os erros humanos podem ter efeitos adversos sobre continentes inteiros e por várias gerações". Reason (1990)

Uma série de acidentes, de repercussão mundial, ocorridos na década de 80, entre os quais: a explosão da Challenger, jan/86; a ruptura do reator de Chernobyl, abril/86; o afundamento do "Herald of Free Enterprise", mar/87; o acidente de Goiânia, set/87; e o acidente de trem de Claphlam Londres, dez/88, fez com que as agências reguladoras e os estudiosos de 
segurança repensassem uma noção bem estabelecida de que acidentes são causados apenas através de ações dos indivíduos. A ênfase moveu-se para a busca de causas mais orgânicas, passando a considerar e avaliar também as causas gerenciais e organizacionais dos desastres.

Neste cenário, as últimas décadas foram testemunhas da crescente abordagem da cultura de segurança em indústrias complexas como a nuclear, aviação civil e petrolífera.

A despeito de tudo que se escreveu sobre cultura de segurança, não há consenso sobre seu conceito, Hopkins (2006). Também não é o propósito desta pesquisa tentar equacionar este problema. A Agência Internacional de Energia Atômica (AIEA), em documento técnico, afirma que:

"A cultura de qualquer organização na indústria nuclear internacional é centrada na segurança...Para uma organização nuclear, a cultura de segurança é o aspecto dominante da cultura organizacional." (TECDOC-1329, 2002)

O conceito de cultura de segurança passou a incorporar muitas outras facetas além daquelas consideradas classicamente em gestão de segurança. O conceito passou a considerar aspectos tais como: liderança, compartilhamento de valores, comunicação aprimorada, aprendizado organizacional, além de enfatizar o estudo dos fatores que conformam 0 comportamento individual e grupal. Desta forma, cultura de segurança passou a receber influências e conhecimentos de diversas fontes de pesquisa e práticas organizacionais, transformando-se em área de conhecimento, cuja importância é reconhecida e promovida por várias companhias, associações, órgãos reguladores e várias outras organizações influentes.

Durante estes anos, após o tema ter ganhado notoriedade e interesse generalizado, as evidências definitivamente sugerem que, embora cultura de segurança possa não ser o único determinante da segurança nas 
organizações, ela desempenha um papel substancial em encorajar as pessoas a se comportarem de modo seguro(Wiegmann,2007).

O estudo dos fatores que conformam o comportamento individual e grupal no tocante à segurança é um desafio interessante e que fornece excelentes subsídios para entender a dinâmica da formação do conjunto de características e atitudes que delineiam a cultura de uma organização. De particular importância é o subconjunto que diz respeito à cultura de segurança conforme a definição do International Safety Advisory GroupINSAG-4, que diz :

"o conjunto de características e atitudes da organização e dos indivíduos que fazem que, com uma prioridade insuperável, as questões relacionadas à segurança nuclear recebam a atenção assegurada pelo seu significado". (INSAG-4, 1991)

É fato notório, que em qualquer ambiente de trabalho, depois de algum tempo, as pessoas sabem a quem recorrer quando necessitam de ajuda ou de algum conhecimento que não dispõem. Esta percepção é seletiva de acordo com os assuntos e as necessidades. Igualmente, muitas pessoas na busca de padrões de comportamento, que as conduzam a um melhor desempenho, observam o comportamento de outras que despertam sua atenção. Este sistema dinâmico ocorre no plano dos valores, construtos mentais e comportamentos, descritos por Schein (1992) e que, de alguma forma tem algum paralelo com o postulado da memética de Dawkins (1989).

É neste contexto, de múltiplas influências entre pessoas ou redes de relacionamentos e conformada pelas características específicas dos artefatos do ambiente de trabalho, que opiniões, explicações e padrões de comportamentos se tornam dominantes no âmbito de uma organização. 


\section{OBJETIVO DO TRABALHO}

\subsection{Objetivo Geral}

Identificar quais são as relações que mais influenciam o comportamento de segurança na área nuclear, especificamente no Instituto de Pesquisa Energéticas e Nucleares - IPEN-CNEN-SP. Para tanto desenvolver uma metodologia que possa ser aplicada em outras organizações também.

\subsection{Objetivos Específicos}

1- Identificar quem são os atores e influências através dos quais os conceitos, valores e atitudes vão gradativamente se modificando e se consolidando em comportamentos individuais e grupais relacionados com a segurança na área nuclear.

2- Identificar os atores, da rede de relacionamentos, que exercem maior influência no comportamento de segurança no IPEN-CNEN-SP.

3- Produzir um importante instrumento para dar subsídio à estratégia dos programas de melhoria de políticas de segurança no IPENCNEN-SP. 


\section{FUNDAMENTAÇÃO TEÓRICA}

A nossa abordagem terá como fio condutor a cultura da segurança e redes sociais, posto que, é objeto de nosso estudo a influência das redes sociais na cultura de segurança. Consequentemente, é de suma importância o alinhamento de alguns conceitos relativos à cultura de segurança e de redes sociais.

\subsection{Foco na Cultura de Segurança}

Nos últimos 30 anos os cientistas que estudam segurança têm direcionado sua atenção ao ambiente organizacional, em particular ao conceito de "cultura de segurança", levando em consideração como manter, modificar e melhorar as respostas ao risco.

Wiegmann et al. (2002) identificaram que as teorias das causas dos acidentes progrediram em vários estágios ao longo do tempo, conforme descritas abaixo :

1 - "A primeira fase é muitas vezes referida como o período técnico, durante o qual a evolução dos novos sistemas mecânicos foram rápidos e mais acidentes foram causados por falhas mecânicas, em especial na concepção, construção e confiabilidade dos equipamentos." .

2 - "A segunda etapa é conhecida como o período de erro humano, onde as falhas do operador humano, ao invés de 
catastróficas avarias mecânicas, foram vistos como a origem do colapso do sistema..."

3 - "A terceira etapa é conhecida como o período sociotécnico. Este ponto de vista sobre erro humano, considera a interação de fatores humanos e técnicos ao explorar as causas de erros e acidentes."

4 - "Finalmente, os últimos anos têm testemunhado o desenvolvimento de uma quarta fase, que é frequentemente chamado de período da cultura organizacional. Esta abordagem reconhece que os operadores não estão realizando suas funções ou interagindo com a tecnologia de forma isolada, mas sim que eles estão atuando como uma equipe coordenada de forma organizacional, que está inserida dentro de uma cultura particular."

Para que possamos compreender bem o significado de cultura de segurança, faz-se necessário a compreensão dos conceitos de cultura e cultura organizacional.

\subsubsection{Cultura}

A cultura, como conceito, tem uma longa e variada história. Cabe destacar a definição clássica do antropólogo britânico Edward B. Taylor, que fez a seguinte definição :

"Cultura...um conjunto complexo no qual estão incluídos conhecimento, crenças, arte, moral, leis, costumes e quaisquer outros hábitos adquiridos pelo homem como membro da sociedade". Taylor (1924) 
Para Dawkins (1989), a maioria do que é habitual sobre o homem pode ser resumida em uma palavra: 'cultura'.

Schein (1992) destaca que a palavra cultura, utilizada pelo leigo, tem a conotação de sofisticação, e que os antropólogos referem-se a cultura como costumes e rituais que as sociedades desenvolveram através dos tempos. Destaca também que nas últimas décadas o termo cultura vem sendo utilizado por pesquisadores e gestores para fazer referência aos valores compartilhados e credos de uma organização.

Das diversas definições sobre cultura, destacamos a mais amplamente aceita, descrita por Schein:

"A cultura de um grupo pode ser definida como um padrão de pressupostos básicos compartilhados que foi aprendido por um grupo que resolveu seus problemas de adaptação externa e integração interna, que tem funcionado bem o bastante para ser considerado válido e, portanto, ser ensinados a novos membros como a maneira correta de perceber, pensar e sentir em relação a esses problemas" Schein (1992).

\subsection{Cultura Organizacional}

Haukelid (2007), observou que a década de 1980 viu o crescimento de um intenso interesse na cultura organizacional e gestão. Observou também que vários livros científicos foram publicados, dos quais "In Search of Excellence" (Peters e Waterman, 1982) e "Corporate Cultures" (Deal e Kennedy, 1982) foram as obras mais conhecidas. Observou também que estes livros descreveram as qualidades das empresas de sucesso e como elas funcionam. Destacou que a maior mensagem destes livros é que as 
corporações com uma cultura forte são bem sucedidas, particularmente se o estilo de gestão enfatizar os valores básicos e os objetivos comuns.

Conceitos e definições de cultura de segurança têm sido obtidos, principalmente, a partir da noção mais geral da cultura organizacional(Wiegmann et al., 2002). Existe uma vasta literatura sobre cultura organizacional, isto se deve ao fato do tema possuir diferentes origens e conceitos dentre os diversos pesquisadores. Nonaka e Takeuchi (1997) destacam que os estudos da cultura organizacional lançaram luz sobre a organização como um sistema epistemológico. Além disso, destacam a importância de fatores humanos como por exemplo: Valores, significados, compromissos, símbolos e crenças...E mais: reconheceram que a organização, como um sistema de significado compartilhado, pode aprender, mudar e evoluir ao longo do tempo através da interação social entre seus membros e entre si mesma e o ambiente.

$\mathrm{Na}$ visão de Hofstede(1990), cultura organizacional é o topo da gestão dos negócios.

Schein (1992), utiliza o termo cultura organizacional como:

"...regularidades comportamentais observadas quando as pessoas interagem (língua, costumes e tradições, rituais), as normas do grupo, os valores adotados, a filosofia formal, as regras do jogo, o clima, incorporado habilidades, hábitos de pensamento / metáforas 'root' modelos mentais e paradigmas lingüísticos, significados compartilhados e / ou integração de símbolos" .

Já Reason (1997) define cultura organizacional como:

“...valores compartilhados (o que é importante) e as crenças (como as coisas funcionam) que interagem com a estrutura da organização e controles sistêmicos para produzir normas comportamentais (o caminho de como faremos as coisas por aqui)".

Richter e Koch (2004) demonstram que a cultura organizacional é o conhecimento compartilhado dentro de uma determinada organização. 
Glendon e Stanton (2000) revelam que a cultura organizacional não é propriedade de nenhum grupo, mas, é criado por todos os membros da organização.

\subsubsection{Definindo Cultura de Segurança}

Não existe um consenso conceitual sobre cultura de segurança, Antonsen (2009). Assim como o conceito de cultura tornou-se conhecido por sua variedade de definições e conceitos, o conceito cultura de segurança também foi definido e utilizado de maneiras diferentes. Segundo Antonsen (2009) o conceito mais citado de cultura de segurança parece ser a definição do Advisory Committee on the Safety of Nuclear Installations (ACSNI,1993), que será abordada à próxima sub-seção.

\subsubsection{A cronologia do termo "Cultura de Segurança"}

O marco das investigações e análises dos acidentes, sob a ótica da cultura de segurança é o acidente de Chernobyl ocorrido em 1986, em que uma cultura de segurança ruim foi identificada como um fator de contribuição importante à causa do acidente, tanto para a os membros da Agência Internacional de Energia Atômica, como para os membros da agência nuclear da Organização para a Cooperação e Desenvolvimento Econômico-OCDE (Cox and Flin 1998; Mearns and Flin 1999; Pidgeon 1998).

A Agência Internacional de Energia Atômica, através do "International Nuclear Safety Group", define Cultura de Segurança como:

"o conjunto de características e atitudes da organização e dos indivíduos que fazem que, com uma prioridade insuperável, as 
questões relacionadas à segurança nuclear recebam a atenção assegurada pelo seu significado". (INSAG,1991).

Pela importância e popularidade, vale destacar outra definição, elaborada pelo Grupo de Estudo de Fatores Humanos do Advisory Committee on Safety of Nuclear Installations (ACSNI) do Reino Unido:

"A cultura de segurança é o produto de valores, atitudes, competências e padrões de comportamento dos indivíduos e do grupo que determinam o compromisso a, e o estilo e a proficiência dos programas de saúde e segurança de uma organização". (ACSNI, 1993):

Como mencionado anteriormente, o interesse atual na cultura da segurança pode ser ligado diretamente às conclusões do acidente nuclear de Chernobyl em 1986. Desde então, inúmeras definições de cultura de segurança têm abundado na literatura de segurança. Estas diversas definições de cultura de segurança são apresentados na TAB. 1, adaptada de Wiegmann (2007), que contém um sumário de pesquisas produzidas na década de 1990, à qual acrescemos a coluna "Área de Atuação" referente ao estudo. 


\section{TABELA 1 - Definições do termo "cultura de segurança" encontradas na} literatura

\begin{tabular}{|c|c|c|c|}
\hline Ano & Definição & Autor & Área de atuação \\
\hline \multirow[t]{3}{*}{1991} & $\begin{array}{l}\text { Cultura de segurança é o conjunto de } \\
\text { características e atitudes da } \\
\text { organização e dos indivíduos que fazem } \\
\text { que, com uma prioridade insuperável, } \\
\text { as questões relacionadas à segurança } \\
\text { nuclear recebam a atenção assegurada } \\
\text { pelo seu significado. }\end{array}$ & $\begin{array}{l}\text { International } \\
\text { Safety Advisory } \\
\text { Group, INSAG-4, } \\
\text { AIEA }\end{array}$ & Nuclear \\
\hline & $\begin{array}{l}\text { Cultura de segurança reflete a atitude, } \\
\text { crença, percepção e valores que os } \\
\text { empregados compartilham em relação a } \\
\text { segurança. }\end{array}$ & $\begin{array}{l}\text { Cox \& Cox } \\
(1991)\end{array}$ & $\begin{array}{l}\text { Gases industriais, } \\
\text { Europa }\end{array}$ \\
\hline & $\begin{array}{l}\text { É o conjunto de crenças, normas, } \\
\text { atitudes, papéis e práticas técnicas e } \\
\text { sociais envolvidas na minimização da } \\
\text { exposição dos empregados, gerência, } \\
\text { clientes e membros do público para } \\
\text { condições perigosas ou prejudiciais. }\end{array}$ & Pidgeon (1991) & $\begin{array}{l}\text { Teórico no contexto } \\
\text { de comportamento } \\
\text { ao volante }\end{array}$ \\
\hline \multirow[t]{2}{*}{1993} & $\begin{array}{l}\text { O conceito de que as crenças e atitudes } \\
\text { da organização manifestadas em } \\
\text { aç̃̃es, políticas e procedimentos afeta o } \\
\text { desempenho da segurança. }\end{array}$ & $\begin{array}{l}\text { Ostrom et al. } \\
\text { (1993) }\end{array}$ & Teórico \\
\hline & $\begin{array}{l}\text { A Cultura de Segurança de uma } \\
\text { organização é o produto de valores } \\
\text { individuais e de grupo, atitudes, } \\
\text { percepções, competências e padrões } \\
\text { de comportamento que determinam o } \\
\text { comprometimento com a cultura de } \\
\text { segurança, e o estilo e proficiência da } \\
\text { gestão de saúde e segurança da } \\
\text { organização. }\end{array}$ & $\begin{array}{l}\text { Grupo de } \\
\text { Fatores } \\
\text { Humanos da } \\
\text { ACSNI do Reino } \\
\text { Unido, em } 1993\end{array}$ & Nuclear \\
\hline 1994 & $\begin{array}{l}\text { Em uma cultura de segurança total } \\
\text { (CST), todos se sentem responsáveis } \\
\text { pela segurança e perseguem isto } \\
\text { diariamente. }\end{array}$ & Geller & Teórico \\
\hline
\end{tabular}




\begin{tabular}{|c|c|c|c|}
\hline \multicolumn{4}{|c|}{...continuação da TABELA 1} \\
\hline \multirow[t]{2}{*}{1996} & $\begin{array}{l}\text { A programação mental coletiva para a } \\
\text { segurança de um grupo de membros da } \\
\text { organização. }\end{array}$ & Berends (1996) & Teórico \\
\hline & $\begin{array}{l}\text { Cultura de segurança é definido como } \\
\text { valores, crenças, pressupostos e } \\
\text { normas compartilhados que governam a } \\
\text { tomada de decisão da organização e as } \\
\text { atitudes dos indivíduos e grupos sobre } \\
\text { a segurança. }\end{array}$ & $\begin{array}{l}\text { Ciavarelli \& } \\
\text { Figlock (Aviação } \\
\text { Naval, US) }\end{array}$ & $\begin{array}{l}\text { Ciavarelli \& Figlock } \\
\text { (Aviação Naval, } \\
\text { EUA) }\end{array}$ \\
\hline \multirow[t]{5}{*}{1998} & $\begin{array}{l}\text { Cultura de segurança refere-se ao alto } \\
\text { valor depositado à segurança do } \\
\text { trabalhador e segurança do público } \\
\text { (nuclear) por todos os indivíduos e } \\
\text { grupos em todos os níveis da planta. } \\
\text { Refere-se, também, a expectativa de } \\
\text { que as pessoas irão agir para preservar } \\
\text { e aperfeiçoar a segurança, assumindo } \\
\text { responsabilidade pessoal pela } \\
\text { segurança e sendo recompensados } \\
\text { consistentemente com estes valores. }\end{array}$ & Carrol (1998) & Nuclear, EUA \\
\hline & $\begin{array}{l}\text { É a união de crenças na importância da } \\
\text { segurança capaz de guiar o } \\
\text { comportamento de um grupo de } \\
\text { indivíduos. e sua compartilhada } \\
\text { compreensão de que todos os membros } \\
\text { voluntariamente sustentam as normas } \\
\text { de segurança do grupo e apóiam outros } \\
\text { membros para este fim. }\end{array}$ & $\begin{array}{l}\text { Helmreich \& } \\
\text { Merrit }\end{array}$ & Aviação - EUA \\
\hline & $\begin{array}{l}\text { Cultura de segurança refere-se a fixar } \\
\text { atitudes e opiniões que um grupo de } \\
\text { pessoas compartilha com respeito a } \\
\text { segurança. É mais estável e resistente } \\
\text { a mudanças que clima de segurança. }\end{array}$ & $\begin{array}{l}\text { Flin, Mearns, } \\
\text { Gordon, \& } \\
\text { Fleming }\end{array}$ & $\begin{array}{l}\text { Plataforma de } \\
\text { exploração de Gás } \\
\text { e Óleo }\end{array}$ \\
\hline & $\begin{array}{l}\text { Cultura de Segurança refere-se a } \\
\text { atitudes arraigadas e opiniões que um } \\
\text { grupo de pessoas compartilham no que } \\
\text { diz respeito à segurança. }\end{array}$ & Lee & $\begin{array}{l}\text { Nuclear, Reino } \\
\text { Unido }\end{array}$ \\
\hline & $\begin{array}{l}\text { A cultura de uma organização é o } \\
\text { produto de valores, atitudes, } \\
\text { percepções, competências e padrões } \\
\text { de comportamento de indivíduos e } \\
\text { grupos que determinam o } \\
\text { comprometimento do gerenciamento da } \\
\text { segurança e saúde na organização. }\end{array}$ & $\begin{array}{l}\text { Cox \& Flin } \\
\text { (Teórico) }\end{array}$ & $\begin{array}{l}\text { Nuclear, Reino } \\
\text { Unido }\end{array}$ \\
\hline
\end{tabular}




\begin{tabular}{|c|c|c|c|}
\hline \multicolumn{4}{|c|}{...continuação da TABELA 1} \\
\hline \multirow[t]{2}{*}{1999} & $\begin{array}{l}\text { Uma cultura de segurança existe dentro } \\
\text { de uma organização onde cada } \\
\text { funcionário, não importa sua posição, } \\
\text { assume um papel ativo na prevenção } \\
\text { de erros sendo apoiado pela } \\
\text { organização. }\end{array}$ & Eiff & Aviação, EUA \\
\hline & $\begin{array}{l}\text { Cultura de segurança trata de questões } \\
\text { de segurança na companhia, } \\
\text { envolvendo percepções de } \\
\text { gerenciamento, supervisão, sistemas de } \\
\text { gerenciamento e percepções da } \\
\text { organização. }\end{array}$ & $\begin{array}{l}\text { Minerals Council } \\
\text { of Austrália }\end{array}$ & $\begin{array}{l}\text { Indústria de } \\
\text { Mineração, } \\
\text { Austrália. }\end{array}$ \\
\hline 2000 & $\begin{array}{l}\text { Cultura de segurança é uma sub faceta } \\
\text { da cultura organizacional, a qual afeta } \\
\text { as atitudes, crenças e valores dos } \\
\text { membros da organização para o } \\
\text { desempenho da segurança e saúde na } \\
\text { organização. }\end{array}$ & Cooper & Teórico \\
\hline 2001 & $\begin{array}{l}\text { Uma cultura de segurança é um } \\
\text { conjunto de pressupostos, e suas } \\
\text { práticas associadas, que permite que } \\
\text { crenças sobre perigos e segurança } \\
\text { sejam construídas. }\end{array}$ & Pidgeon & $\begin{array}{l}\text { Teórico no contexto } \\
\text { de comportamento } \\
\text { ao volante }\end{array}$ \\
\hline
\end{tabular}

Podemos perceber que dos 17 conceitos, cinco (29\%) são oriundos do setor nuclear, e que predomina nestes conceitos o fator "atitude" em relação a segurança.

\subsubsection{A cultura de segurança pela Agência Internacional de Energia Atômica}

A Agência Internacional de Energia Atômica é um organismo que, como importante agente que zela pelo fator segurança, quanto aos aspectos de cultura de segurança, afirma:

"A cultura de qualquer organização na indústria nuclear internacional é centrada na segurança. Isto reflete a consciência da significativa capacidade destrutiva da energia nuclear quando o seu controle é perdido, e o reconhecimento de que a atenção 
estrita à segurança é essencial. Para uma organização nuclear, a cultura de segurança é o aspecto dominante da cultura organizacional." (TECDOC-1329, 2002).

A Agência Internacional de Energia Atômica refere-se aos pontos que são os alicerces para a segurança operacional(TECDOC-1329, 2002):

1. Existência de planos estratégicos e os planos de ação com a segurança integrada a todos os aspectos de atividades da organização;

2. Presença e a qualidade dos sistemas de controle dos riscos da organização;

3. Presença e a qualidade do sistema de informações gerenciais da segurança da organização;

4. Extensão à qual cada empregado recebe o treinamento de integração no trabalho de alta qualidade e treinamento de segurança.

Todos os elementos mencionados acima desempenham um importante papel no estabelecimento de bons alicerces para a segurança na organização. Esses elementos, individualmente ou em conjunto não constituem uma cultura de segurança, embora eles sejam uma parte importante dela. Estes elementos podem ser observados; estão, portanto no nível mais externo (nível de artefatos) do modelo de três níveis da cultura organizacional proposto por Schein(1992).

A Agência Internacional de Energia Atômica possui relevantes publicações a respeito de cultura de segurança (TECDOC-1321, 2002), conforme demonstrado na TAB. 2. 
TABELA 2 -Principais publicações da AIEA a respeito de cultura de segurança

\begin{tabular}{|c|c|c|}
\hline Documento & Título & Objetivo \\
\hline INSAG-4 & $\begin{array}{l}\text { SAFETY } \\
\text { CULTURE }\end{array}$ & $\begin{array}{l}\text { Visa a promoção da cultura de segurança, } \\
\text { definindo o conceito que se refere a } \\
\text { organizações e indivíduos envolvidos em } \\
\text { atividades nucleares. Ele fornece uma } \\
\text { referência útil para avaliar a eficácia da } \\
\text { cultura de segurança em uma organização, } \\
\text { de modo que as melhorias em potencial } \\
\text { podem ser identificadas. }\end{array}$ \\
\hline $\begin{array}{l}\text { Safety Reports } \\
\text { Serie } N^{\circ} 1\end{array}$ & $\begin{array}{l}\text { Examples of } \\
\text { Safety Culture } \\
\text { Practices }\end{array}$ & $\begin{array}{l}\text { Este relatório inclui uma seleção } \\
\text { internacional de exemplos de práticas que } \\
\text { ilustram atributos específicos da cultura de } \\
\text { segurança, tal como consta no INSAG-4. } \\
\text { Os exemplos são aqueles comumente } \\
\text { observados em instalações nucleares, ou } \\
\text { se não estiver em uso generalizado, para } \\
\text { representar as práticas de fundamental } \\
\text { importância para o desenvolvimento da } \\
\text { cultura de segurança. }\end{array}$ \\
\hline $\begin{array}{l}\text { Safety Reports } \\
\text { Serie } N^{\circ} 11\end{array}$ & $\begin{array}{l}\text { Developing } \\
\text { Safety Culture } \\
\text { in Nuclear } \\
\text { Activities }\end{array}$ & $\begin{array}{l}\text { Apresentar sugestões práticas sobre como } \\
\text { desenvolver, melhorar e avaliar a cultura } \\
\text { de segurança. O relatório reconhece a sua } \\
\text { natureza evolutiva e é de valor para todas } \\
\text { as organizações, independentemente de } \\
\text { qual estágio de desenvolvimento da cultura } \\
\text { de segurança está. Este relatório inclui } \\
\text { uma lista de sintomas de uma cultura de } \\
\text { segurança fraca. }\end{array}$ \\
\hline AIEA-TECDOC-743 & $\begin{array}{l}\text { ASCOT - } \\
\text { Guidelines }\end{array}$ & $\begin{array}{l}\text { Orientações para a auto-avaliação da } \\
\text { cultura de segurança das organizações e } \\
\text { para as revisões do ASCOT }\end{array}$ \\
\hline
\end{tabular}

\subsection{A Memética e a Replicação da Cultura}

O final dos anos 1980 despontou uma teoria, como alternativa para o estudo de cultura, chamada memética. Este termo foi cunhado pelo cientista e professor da Universidade de Oxford, Richard Dawkins que afirma que: 
“...a transmissão cultural é análoga à transmissão genética no que, embora basicamente conservadora, pode dar origem a uma forma de evolução".. Dawkins (1989).

Dawkins conceitua meme da seguinte forma:

“...'meme' pode ser definida como uma entidade que é capaz de ser transmitida de uma mente para outra... Os memes se propagam no conjunto de memes pulando de mente para mente através de um processo que, em sentido amplo, pode ser chamado de imitação. Memes podem ser músicas, ou modas, ou rituais, formas de fazer as coisas, valores ou padrões de comportamento". Dawkins (1989).

\subsection{Análise de Redes Sociais}

Para Emirbayer e Goodwin (1994) redes sociais são conjuntos de contatos que ligam vários atores, que podem ser de diferentes tipos, apresentarem conteúdos diferentes, bem como diferentes propriedades estruturais. Já Wasserman e Faust, (1994) definem redes sociais como um conjunto de dois elementos: atores (pessoas, instituições ou grupos) e suas conexões.

A análise de redes sociais de um sistema social é, antes de tudo, um conjunto estruturado de posições sociais. O conceito de papel aparece como uma variável dependente da posição. Em conseqüência, as dimensões valorativas e normativas da conduta são, para a análise de redes sociais, assim como as demais dimensões da motivação, mais efeito que causa. 
Para Wasserman e Faust (1994) a análise de redes sociais é baseada no conceito de que as relações entre unidades são importantes. Por isso, as relações definidas por ligações entre partes são componentes fundamentais da abordagem relacional. Podemos então utilizar alguns conceitos relacionais em análise de redes: i) os atores e suas ações são vistos como interdependentes, ii) laços relacionais (ligações) entre atores são canais para transferência, ou fluxo, de recursos (tanto material como não-material).

Segundo Rossoni e Guarido Filho (2007, p. 74) existem diversas formas de analisar redes sociais. Então, inúmeras modalidades podem ser utilizadas para avaliar as características das redes de cooperação. Entre essas, as mais frequentemente encontradas em trabalhos empíricos são:

i) centralidade,

ii) coesão,

iii) análise posicional e

iv) análise de small worlds.

Tendo em vista o objetivo deste estudo, será utilizada a primeira abordagem.

\subsubsection{Indicadores de Análise de Redes Sociais Utilizados}

Um dos usos mais comuns da análise de redes sociais é identificar os atores mais importantes em uma rede social, ou melhor, aqueles atores mais centrais. A centralidade pode ser vista como uma propriedade dos atores, inseridos em uma determinada rede (Wasserman e Faust, 1994). Para mensurar centralidade existem duas categorias de métricas: local e global. Um ator é localmente central se ele apresenta um número maior de conexões com outros. Porém, esse ator será globalmente 
central se ocupa uma posição estratégica na rede de uma forma geral(Scott,2000). Utilizaremos neste estudo as métricas descritas abaixo:

Uma Rede Social é um conjunto de $\mathrm{N}$ atores ou agentes, entre os quais exista um ou mais tipos de relacionamento. Para representar uma rede social nós lançamos mão de um grafo, onde os atores são representados por nós ou pontos e cada ligação de relacionamento é representado por um arco ou aresta ligando os atores relacionados e indicando o sentido da relação. Como existe um isomorfismo entre grafos e matrizes, para facilitar as análises, tais grafos são representados por matrizes, nos respectivos programas de computador que modelam redes sociais.

A distância entre dois nós é medida pelo número de arestas que temos que percorrer para ir de um ao outro. Como, via de regra, há vários caminhos possíveis, aquele de menor distância é chamado de caminho geodésico. Normalmente, quando se fala de distância entre dois nós, é na distância geodésica em que se está interessado.

Uma vez calculadas as distâncias (geodésicas) entre todos os nós é possível construir a matriz geodésica com todas estas distâncias e que serve de base para vários cálculos auxiliares. À máxima destas distâncias dá-se o nome de diâmetro da rede. Note que os nós que não tem conexão teriam distâncias infinitas entre si, mas na matriz geodésica, estes componentes são deixados nulos. 


\subsubsection{Métricas para avaliar a rede como um todo :}

- Distância Média:

É a média de todas as distâncias geodésicas da rede, excluindose as "infinitas".

- Densidade

É a relação entre o número de arestas existente em relação ao número máximo possível em uma rede.

- Fragmentação

É a proporção de nós de uma rede que são desconectados.

- Reciprocidade.

É a percentagem de conexões que são recíprocas (bidirecionais), este indicador serve também para dar uma indicação da coesão da rede.

- Uma outra análise da rede como um todo, será feita com o seguinte procedimento:

o Primeiro eliminaremos os nós isolados e depois os pendentes e calcularemos o que isto produziu em termos de redução percentual do número de nós.

o Isto feito analisaremos se a rede reduzida apresenta ainda algum nó que seja "boundary spanner", ou seja, se for removido fragmentará a rede. 


\subsubsection{Métricas para avaliar influências dos atores na rede}

É importante ressaltar que, além dos índices relacionados abaixo, eventualmente, algum outro índice poderá ser usado para esclarecer alguma dúvida específica que surja na análise. Então temos:

- Grau de Centralidade Total ou Grau Total ("Total Degree" )

Considerando um nó, e contando todos os arcos que estão chegando nele encontra-se o grau de entrada (in degree) deste nó. Da mesma forma contando-se os arcos que estão saindo dele obtem-se o grau de saída (out degree). Somando-se os dois indicadores anteriores obtem-se o grau total (total degree).

Em uma rede de comunicação entre pessoas, um alto grau de entrada indica aquelas que recebem informações de muitos atores (os bem informados). Aquelas com elevado grau de saída, normalmente são pessoas que transmitem as informações e que transmitem conhecimento para muitas outras.

Em redes de influência, as pessoas com alto grau de entrada são aquelas que recebem influência de diversas outras e as de alto grau de saída são aquelas que influenciam várias outras. Neste caso não é bom que haja um desbalanceamento, ou seja:

o Atores com alto grau de saída devem ter pelo menos um grau de entrada razoável, senão sua influência pode ser inteiramente desconexa do grupo e estar causando tensões desnecessárias;

o Igualmente, receber muita influência (alto grau de entrada), mas ter baixo grau de saída, pode indicar atores com baixa capacidade de aprendizado ou que 
não conseguem firmeza de seus conceitos, ou mesmo que tenham dificuldades em se comunicar ou transmitir seus entendimentos.

o Portanto ao observarmos o grau total dos atores mais proeminentes verificaremos também se o balanceamento está aceitável.

- Número de Cliques ("Clique Count”)

Um clique é subgrafo completo, ou seja, é uma subrede (partição da rede) na qual cada ator (nó) tem todas as conexões (arestas) possíveis com os demais atores desta subrede. Obviamente que o interesse se dá por cliques não triviais, ou seja, de 3 ou mais elementos. Tais grupos por serem extremamente ligados acabam por ter um poder de influência coletiva maior. Portanto um ator que faça parte de vários cliques acaba tendo seu "poder" de influência amplificado. Devido a estas considerações o número de cliques (a que o ator pertence) é também um indicador de centralidade.

- Centralidade de Aglutinação ( "hub centrality")

No caso de redes simétricas ou quase simétricas a centralidade de autovetor indica atores que são importantes (centrais), porque estão conectados a muitos atores que também tem muitas conexões. Desta forma a influência deste ator tem mais capilaridade. Normalmente nós com alta contagem de cliques também terão um bom escore neste indicador. O software ORA calcula o autovetor correspondente ao maior auto valor da matriz de adjacências (simetrizada) e os componentes deste vetor (após normalização) são os indicadores dos agentes. 
No caso de rede direcionada e com matriz não muito próximas da simetria, este indicador não é tão preciso e há uma generalização proposta por Kleinberg (1998) que calcula 2 indicadores complementares, designado como as centralidades de autoridade e aglutinação.

Vejamos o caso de uma rede de citações, quando ao se escrever um artigo, citam-se trabalhos que são realmente centrais ao escopo da pesquisa. Os trabalhos dito centrais são assim avaliados porque já foram citados por muitos outros (especialmente por artigos que fazem revisão do estado da literatura). Por outro lado se você consultou muitos trabalhos centrais relevantes é provável que o seu trabalho esteja trazendo uma contribuição que despertará curiosidade nos outros e pode acabar se tornando relevante também. Para tais casos vale a pena considerar dois tipos de centralidades complementares, a saber: de autoridade ou aglutinação.

Trabalhos que são vastamente citados teriam altos valores do primeiro indicador (autoridade) e trabalhos que citam inúmeros trabalhos, teriam altos valores do segundo (centralidade de aglutinação ou hub). É incomum um ator ter alta centralidade de hub sem ter um valor razoável na de autoridade e vice-versa. No caso das redes de influência que estamos pesquisando, especulase que um ator com alto valor na centralidade de aglutinação deve ter um vetor cultural mais próximo do centróide da população do que a maioria dos outros.

O conceito é que, nós com altos valores de centralidade de autoridade têm muitos arcos que chegam até ele oriundos de nós com altos valores de centralidade de aglutinação. Por outro lado nós com altos valores de centralidade de aglutinação são aqueles que apontam para muitos nós com alta 
centralidade de autoridade. Daí veio a conjectura feita acima, se alguém é influenciado por pessoas que por sua vez influenciam muitas pessoas, esta pessoa deve acabar tendo um vetor cultural que não fique longe da média (centróide) da cultura da rede. Isto será comentado nas análises.

- Centralidade de Intermediação ("betweenness centrality").

Suponha que para cada par de nós da rede seja feita uma contagem dos caminhos geodésicos existentes entre eles e depois seja calculada qual a percentagem destes caminhos que passam pelo nó $x$. Este indicador é a centralidade de intermediação do nó x. Se estivermos tratando de uma rede de comunicação, pessoas com valores mais elevados deste indicador são normalmente as que entram em contato com a maior diversidade de informações. Este indicador, no entanto, só é calculado para redes simétricas e no nosso caso, o ORA faz a simetrização a maior (por união). 


\section{METODOLOGIA EXPERIMENTAL}

\subsection{Método I}

Optamos, neste trabalho, quanto à natureza, pela pesquisa exploratória porque essa busca obter primeiramente a familiaridade do pesquisador com o problema focalizado e, posteriormente, conforme a necessidade incluir novos formalismos de análise dos dados obtidos. Quanto ao método, optou-se pela pesquisa de campo, pela natureza do estudo, posto que precisávamos ter um mapeamento preciso das relações no IPENCNEN-SP.

O protocolo de pesquisa aplicado neste trabalho abrangeu as etapas: 1) destaque da relevância do tema; 2) revisão da literatura; 3) detalhamento do tema; 4) critérios de seleção da amostra; 5) a estratégia de condução da pesquisa de campo; 6) a análise dos dados e; 7) as conclusões do trabalho.

\subsection{Método II}

Buscamos na literatura estudos de abordagens teóricas e práticas que utilizassem conceitos sócio-antropológicos. Resultando na busca de estudos que validassem modelos conceituais, visando captar e sintetizar as principais dimensões de análise, que pudessem comprovar as variáveis preditoras de comportamento seguro em ambientes em que a segurança seja de vital importância. 
Identificamos então, inúmeros atributos que podem caracterizar uma cultura de segurança positiva e extraímos quatro atributos, ou características (Dimensões) que nos permitissem mapear e entender as redes sociais, definidas pelas relações, que influenciam sobre a formação e manutenção de uma cultura de segurança, quais sejam: Visão de segurança; abertura e comunicação (Direta e Indireta), colaboração e trabalho em equipe e aprendizagem organizacional. Esta escolha foi baseada no fato de que estes itens encontram-se presentes em grande parte dos modelos e questionários de avaliação de cultura de segurança que encontramos na literatura.

Cada dimensão nos identificou uma rede de relacionamento, associadas às questões. Então, a partir dai, elaboramos três questionários: Um para levantamento da população a ser pesquisada, outro para o mapeamento das redes de influências e um terceiro para levantamento de opinião sobre aspectos de segurança (Que chamamos de questionário de crenças).

Nossa pesquisa está contextualizada no âmbito do IPEN-CNEN-SP, e a fizemos em 3 etapas, descritas na subseção "Técnica Utilizada" do capítulo "Encaminhamento da pesquisa".

\subsection{O Método da Pesquisa}

Conforme mencionado à seção 3.2, efetuamos busca na literatura de abordagens teóricas e práticas que utilizassem conceitos sócioantroplógicos. Buscamos inicialmente, trabalhos com enfoque na área nuclear, que possuíssem questionários de cultura de segurança (clima), devidamente testados e avaliados por métodos estatísticos aplicados em mais de uma instância de tempo. Porém, embora encontrássemos vários trabalhos e questionários de avaliação, não encontramos as validações 
estatísticas de seus respectivos modelos conceituais. Este fato nos levou a analisar trabalhos em outras áreas que possuíssem alto grau de "criticidade", no que diz respeito à segurança. Como por exemplo plataformas petrolíferas (Tharaldsen, 2007) e empresas do ramo da construção civil (Pousette, 2006).

Estes estudos foram conclusivos em suas abordagens psicométricas e usando estatística multivariada eles comprovaram a validade de seus respectivos modelos conceituais. Além disso, foram realizados estudos longitudinais e multigrupo que deram mais robustez na comprovação do valor preditivo de certas variáveis (Cheyne,1998 et al.) e Pousette (2006).

Confrontamos estas dimensões com as dimensões das características e atitudes de cultura de segurança identificadas pela Agência Internacional de Energia Atômica (SCART,2008), para identificar o que é substancialmente "idêntico". Neste sentido efetuamos a referência cruzada entre as dimensões dos seguintes estudos: (a) Pousette(2006); (b) HSE(2001); (c) Obadia(2004) e; (d) SCART(2008).

Identificamos então, inúmeros atributos que podem caracterizar uma cultura de segurança positiva e extraímos quatro daqueles que mais apareciam nos diversos estudos, dando maior ênfase aos estudos que testaram estatisticamente seus modelos. Uma vez escolhidos, concebemos as questões que nos permitissem mapear e entender as redes sociais que influenciam sobre a formação e manutenção destas características de uma cultura de segurança, quais sejam:

1. Visão de segurança;

2. Abertura e comunicação (Direta e Indireta);

3. Colaboração e trabalho em equipe e;

4. Aprendizagem organizacional. 
Cada dimensão nos identificou uma rede de relacionamento, associadas às questões. Então, a partir dai, elaboramos dois questionários:

1. Levantamento das redes de relacionamentos;

2. Levantamento de opinião sobre aspectos de segurança (Que chamamos de questionário de crenças).

\subsection{Técnica Utilizada}

Nossa pesquisa está contextualizada no âmbito do IPEN-CNEN-SP, no qual utilizamos a técnica de pesquisa tipo bola de neve ("snowball") para mapeamento das redes sociais de nosso interesse, conforme demonstrado no fluxo do levantamento de redes (ANEXO D). Nesta etapa fizemos o levantamento dos especialistas e outros atores influentes no comportamento de segurança da organização.

Esta pesquisa foi dividida em três etapas, a saber:

1. Efetuamos a pesquisa SEMENTE onde solicitamos a um grupo de gerentes dos vários centros de pesquisa do IPEN-CNEN-SP que indicassem uma lista de pessoas que, em sua visão, representassem atores importantes na formação dos valores e pressupostos básicos relativos à segurança no contexto onde trabalham.

2. Utilizamos a técnica de levantamento "snowball" . Esta técnica consiste em começarmos a pesquisa com um ator central ou conjunto de atores. Em nosso caso, começamos com as pessoas indicadas na etapa 1. Cada um desses atores é convidado a indicar alguns ou todos os seus vínculos com outros atores. Então, todos os atores indicados (que não faziam parte da lista original) são também convidados a indicar 
seus vínculos. O processo continua até que não são identificados novos atores, ou até que decidimos parar, ou porque a percentagem de novos atores em cada rodada tornou-se insignificante perante a população levantada.

3. Efetuamos o envio do questionário de crenças, com 10 perguntas, (ANEXO C) aos atores que tiveram três, ou mais indicações, no levantamento de redes snowball. É importante destacar que, para tratarmos as 10 questões de crenças em nossa análise, utilizamos uma escala intervalar com elemento neutro.

\subsection{Metodologia da Pesquisa e Estrutura do Questionário}

\subsubsection{A Pesquisa Semente}

A pesquisa semente foi elaborada visando obter uma indicação para os primeiros funcionários a serem pesquisados na segunda fase (dar início à pesquisa "bola de neve"). Primeiramente fizemos contatos telefônicos e posteriormente envio de "carta convite" aos gerentes dos Centros (ANEXO A). Os resultados apresentados constam às linhas correspondentes ao ciclos 1 e 2 da TAB. 3. Os nomes indicados nesta fase obedeceram aos seguintes critérios:

- Aqueles que, por sua função, têm que tomar decisões ou ações com possível impacto na segurança; 
- Aqueles que, por seu conhecimento a respeito deste tema, são consultados ou ouvidos com atenção sempre que manifestam sua opinião em assuntos de segurança e;

- Aqueles que, por sua forma de agir, sempre ciosos de manter um comportamento seguro em todas suas tarefas, são assim reconhecidos por seus pares.

\subsubsection{A Pesquisa Bola de Neve}

Com o resultado da pesquisa semente demos início ao levantamento das redes, utilizando a técnica de levantamento bola de neve ("snowball"). Este questionário (ANEXO B) foi elaborado visando obter o mapeamento das redes de influência relativas à cultura de segurança no IPEN-CNEN-SP. Os resultados constam às linhas 3, 4 e 5 da TAB. 3.

\subsubsection{Aplicação do Questionário de Crenças - Aspectos de Segurança}

Com o resultado da pesquisa bola de neve, enviamos 0 questionário de crenças aos funcionários que obtiveram, três ou mais, indicações nas pesquisas. Os resultados apresentados, referentes à aplicação do questionário, constam à linha 6 da TAB. 3. 
TABELA 3 - Sumário do processo de levantamento de redes e crenças

\begin{tabular}{|c|c|c|c|c|c|}
\hline Ciclo & Fase & Público Alvo & $\begin{array}{l}\text { Forma de } \\
\text { acesso }\end{array}$ & $\begin{array}{l}\text { Novas } \\
\text { Indicações }\end{array}$ & Qtde. Final \\
\hline 1 & $\begin{array}{l}\text { Indicação dos } \\
\text { Gerentes dos } \\
\text { Centros }\end{array}$ & Gerentes & Carta Convite & 10 & 10 \\
\hline 2 & $\begin{array}{l}\text { Pesquisa } \\
\text { Semente }\end{array}$ & $\begin{array}{l}\text { Indicados pelos } \\
\text { gerentes }\end{array}$ & $\begin{array}{l}\text { Questionário } \\
\text { respondido no } \\
\text { software } \\
\text { Limesurvey }\end{array}$ & 29 & 39 \\
\hline 3 & Bola de neve 1 & $\begin{array}{l}\text { Indicados na Pesq } \\
\text { Semente }\end{array}$ & $\begin{array}{l}\text { Questionário } \\
\text { entregue em } \\
\text { mãos }\end{array}$ & 23 & 62 \\
\hline 4 & Bola de neve 2 & $\begin{array}{l}\text { Indicados na Pesq } \\
\text { Bola de Neve } 1\end{array}$ & $\begin{array}{l}\text { Questionário } \\
\text { entregue em } \\
\text { mãos }\end{array}$ & 13 & 75 \\
\hline 5 & Bola de neve 3 & $\begin{array}{l}\text { Indicados na Pesq } \\
\text { Bola de Neve } 2\end{array}$ & $\begin{array}{l}\text { Questionário } \\
\text { entregue em } \\
\text { mãos }\end{array}$ & 9 & 84 \\
\hline 6 & $\begin{array}{l}\text { Questionário de } \\
\text { CRENÇAS }\end{array}$ & $\begin{array}{l}\text { Os mais } \\
\text { indicados }\end{array}$ & $\begin{array}{l}\text { Questionário } \\
\text { de crenças }\end{array}$ & -39 & 45 \\
\hline 7 & \multicolumn{5}{|c|}{ Nesta fase, das 84 indicações, 45 responderam ao questionário de CRENÇAS } \\
\hline
\end{tabular}

É Importante ressaltar que as redes estudadas neste trabalho foram compostas por 45 funcionários que foram indicados no levantamento das redes (bola de neve) e que responderam ao questionário de crenças.

\subsection{Compilação dos Levantamentos}

Efetuamos a compilação dos dados apurados na etapa de levantamento de redes, utilizando um software para análise de redes sociais ORA. Este software foi desenvolvido pela universidade Instituto de Pesquisas da Universidade Carnegie Mellon, e traz consigo um robusto ferramental para geração dos sociogramas ou gráficos de redes, bem como relatórios que disponibilizam uma gama de indicadores para a análise das redes sociais. Para avaliar a rede como um todo, usamos as seguintes métricas: 
- Distância Média;

- Densidade;

- Fragmentação e;

- O número de boundary spanners na rede reduzida, conforme explicado na página 34.

Para identificar os atores mais influentes em cada rede, os seguintes indicadores foram escolhidos:

- Grau de centralidade de um nó (“Total Degree”);

- Número de Cliques (“Clique Count”);

- Centralidade de aglutinação ("Hub Centrality") e;

- Centralidade de Intermediação ("Betweenness Centrality").

\subsection{O Vetor Cultural}

Não é pretensão deste trabalho propor que 10 variáveis sejam suficientes para caracterizar completamente a cultura de segurança de uma organização. Por outro lado estas variáveis foram escolhidas tendo como base indicadores presentes em vários modelos de avaliação de cultura de segurança colhidos na literatura. Desta forma estes 10 indicadores servem para dar uma caracterização adequada do posicionamento de cada indivíduo em relação à cultura de segurança no IPEN-CNEN-SP.

Consideremos um espaço decadimensional, cujas coordenadas seriam, respectivamente, cada um dos indicadores. Neste espaço o vetor cultural de cada pessoa pode ser representado por um ponto, localizado por 
dez coordenadas. Esta distribuição de (45) pontos representa a "cultura de segurança" da população pesquisada (45 pessoas).

Nosso argumento é que se: (a) as redes de influência foram bem mapeadas; (b) são significativas para a formação da cultura; e (c) os indicadores de atores mais relevantes foram bem escolhidos; então: os atores mais destacados terão seus vetores culturais mais próximos do centróide, mais do que a média geral da população.

Com base no vetor cultural de cada um dos 45 funcionários pesquisados, calculamos as coordenadas do centróide e posteriormente, usando a distância euclidiana, calculamos a distância de cada vetor até o centróide. O resultado do comportamento do vetor cultural, está demonstrado à TAB. 4, que identifica os cinco atores mais influentes, grafando-os em negrito. 
TABELA 4 - Comportamento do vetor cultural dos 45 funcionários que responderam ao questionário de crenças.

\begin{tabular}{rc}
\hline ID & $\begin{array}{c}\text { Distância do } \\
\text { Centróide }\end{array}$ \\
\hline $\mathbf{1 0 0}$ & $\mathbf{1 , 2 0 6 7 7 1 0 2}$ \\
\hline 123 & 1,24305478 \\
\hline 166 & 1,82898474 \\
\hline 37 & 1,86507869 \\
\hline 104 & 1,96374548 \\
\hline $\mathbf{1 1 3}$ & $\mathbf{2 , 0 9 5 1 4 4 3 0}$ \\
\hline $\mathbf{5 7}$ & $\mathbf{2 , 1 1 6 2 5 1 0 5}$ \\
\hline 12 & 2,16811917 \\
\hline 91 & 2,28294806 \\
\hline 101 & 2,33111005 \\
\hline 105 & 2,40616492 \\
\hline 124 & 2,46996776 \\
\hline 78 & 2,51012763 \\
\hline 79 & 2,55400919 \\
\hline $\mathbf{3 1}$ & $\mathbf{2 , 6 1 4 2 0 6 2 0}$ \\
\hline 33 & 2,80686988 \\
\hline 80 & 2,81477583 \\
\hline 15 & 2,84227348 \\
\hline 5 & 2,87724148 \\
\hline 66 & 2,95346626 \\
\hline 54 & 2,95722593 \\
\hline 4 & 3,08232716 \\
\hline 59 & 3,17116639 \\
\hline 99 & 3,22674013 \\
\hline 96 & 3,25075490 \\
\hline 106 & 3,28813805 \\
\hline 44 & 3,40761674 \\
\hline 7 & 3,45618072 \\
\hline 46 & 3,47541631 \\
\hline 117 & 3,48180456 \\
\hline &
\end{tabular}




\begin{tabular}{rr}
\hline 86 & 3,50089936 \\
\hline 25 & 3,57315091 \\
\hline 23 & 3,70744996 \\
\hline 50 & 3,95961090 \\
\hline 29 & 4,09208812 \\
\hline 52 & 4,23355205 \\
\hline 94 & 4,72236601 \\
\hline 51 & 4,84317007 \\
\hline 9 & 5,10235966 \\
\hline 69 & 5,16727595 \\
\hline 47 & 5,48438862 \\
\hline 18 & 5,76297248 \\
\hline 103 & 6,09103774 \\
\hline 42 & 6,17977586 \\
\hline 10 & 6,71570851 \\
\hline
\end{tabular}




\section{RESULTADOS - ANÁLISE DAS REDES}

\subsection{A Conformação das Redes Estudadas}

O estudo teve a finalidade de identificar quais são as relações que mais influenciam o comportamento de segurança no IPEN-CNEN-SP. Do estudo podemos destacar as seguintes redes:

- Rede Agregada - Composta pelo total de indicações do questionário, considerando as 4 dimensões de estudo, descritas na explicação do modelo (Subseção "O método da Pesquisa" do Capítulo 3). Tecnicamente esta rede deveria ser chamada de multirede, pois ela agrega quatro redes.

- Rede Visão de Segurança - Composta pelo total de indicações do questionário de levantamento de redes, considerando apenas as questões associadas a esta dimensão de estudo.

- Rede Abertura e Comunicação - Composta pelo total de indicações do questionário de levantamento de redes, considerando apenas as questões associadas a esta dimensão de estudo.

- Rede Trabalho em Equipe - Composta pelo total de indicações do questionário de levantamento de redes, considerando apenas as questões associadas a esta dimensão de estudo.

- Rede Aprendizagem Organizacional - Composta pelo total de indicações do questionário de levantamento de redes, considerando apenas as questões associadas a esta dimensão de estudo. 


\subsection{Rede Agregada (Multirede Agregada)}

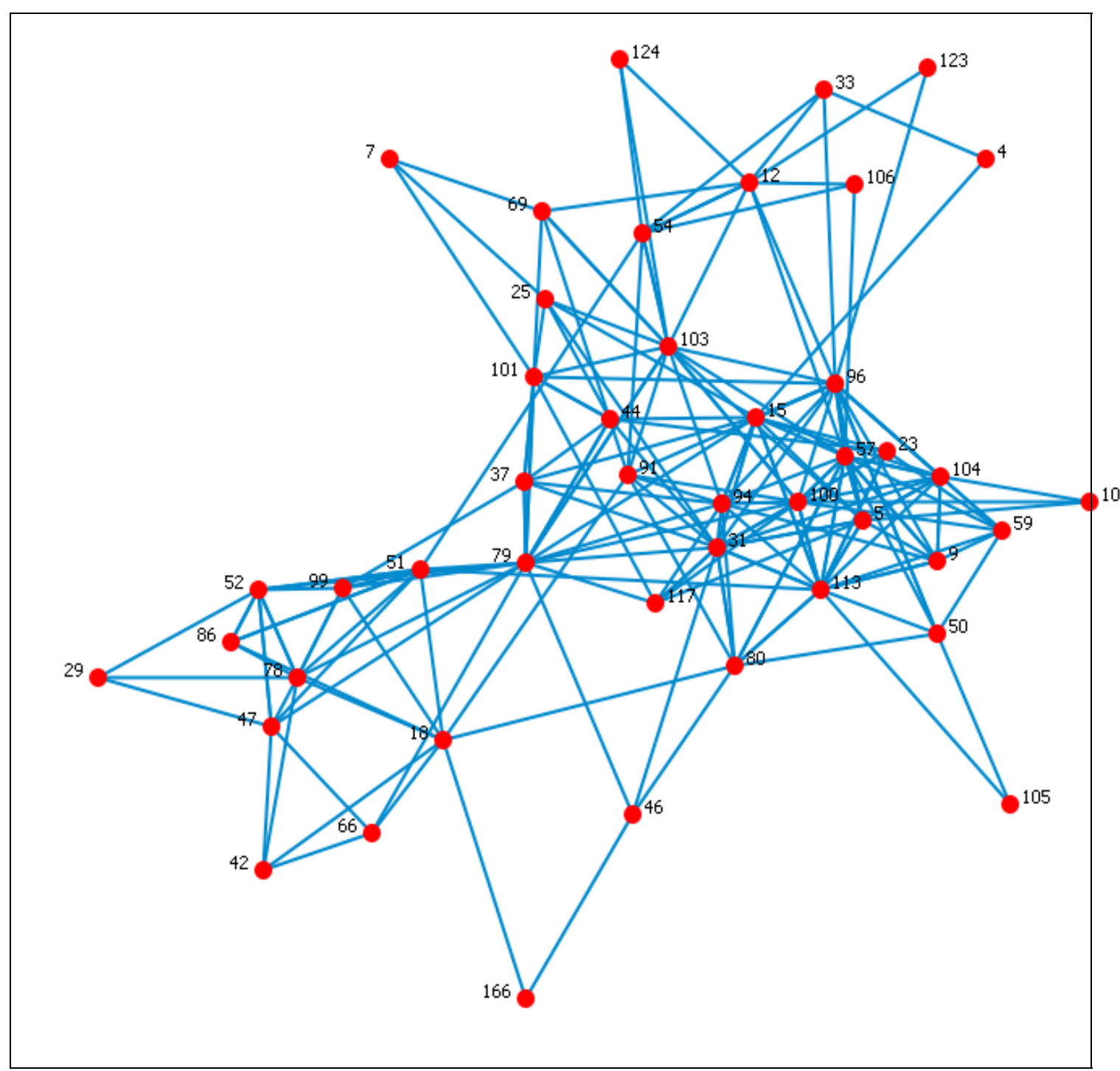

Figura 1 - Rede de influências de cultura de segurança dos funcionários do IPEN-CNEN-SP

Vemos acima a figura 1 que nos apresenta a configuração da rede global de influências e à TAB. 5 são demonstrados as características globais e alguns indicadores das redes que compõem a rede principal: 
TABELA 5 - Características e Indicadores da Rede Multiagregada

\begin{tabular}{lc}
\hline Indicadores & Multirede \\
\hline & $\mathrm{VS}+\mathrm{AC}+\mathrm{TE}+\mathrm{AO}$ \\
\hline $\mathrm{N}^{\circ}$ de Nós & 45 \\
\hline $\mathrm{N}^{\circ}$ de Ligações & 211 \\
\hline $\mathrm{N}^{\circ}$ de Componentes & 1 \\
\hline $\mathrm{N}^{\circ}$ Pendentes & 0 \\
\hline Fragmentação & 0 \\
\hline Densidade & 0,11 \\
\hline Reciprocidade & $25 \%$ \\
\hline Distância Média & 2,45 \\
\hline
\end{tabular}

\subsection{Base Para Análise dos Atores Mais Influentes na Rede de Influências}

A TAB. 6 refere-se à seleção dos funcionários mais influentes nas redes, e tomamos como base o relatório "Key Entities: Who" extraído do software ORA, que classifica os atores mais influentes, a partir da quantidade de vezes que este ator aparece entre os 3 maiores índices de um universo de 10 indicadores. Fizemos as seguintes adaptações: O ranking obtido, considerou os cinco maiores valores dos 4 índices de medidas, descritos na subseção "Métricas para Identificar Influência dos Atores da Rede" do capítulo "Análise de Redes Sociais", a saber:
a) Grau de centralidade;
b) Número de cliques;
c) Centralidade de aglutinação;
d) Centralidade de intermediação. 
TABELA 6 - Base para contagem do ranking dos funcionários mais influentes na rede

\begin{tabular}{lccccc|ccccc|ccccc}
\hline Índice & \multicolumn{4}{c}{ Visão Segurança } & \multicolumn{4}{c}{ Visão Comunicação } & \multicolumn{5}{c}{ Trabalho em Equipe } \\
Considerado & 1 & 2 & 3 & 4 & 5 & 1 & 2 & 3 & 4 & 5 & 1 & 2 & 3 & 4 & 5 \\
\hline $\begin{array}{l}\text { Total de grau de } \\
\text { centralidade }\end{array}$ & 31 & 57 & 113 & 94 & 96 & 79 & 113 & 31 & 100 & 103 & 113 & 5 & 9 & 15 & 104 \\
\hline $\begin{array}{l}\text { Número de } \\
\text { cliques }\end{array}$ & 31 & 113 & 57 & 94 & 100 & 31 & 57 & 79 & 113 & 5 & 15 & 104 & 113 & 9 & 78 \\
\hline $\begin{array}{l}\text { Centralidade de } \\
\text { aglutinação }\end{array}$ & 57 & 166 & 31 & 94 & 113 & 42 & 52 & 113 & 99 & 100 & 113 & 5 & 59 & 57 & 9 \\
\hline $\begin{array}{l}\text { Centralidade de } \\
\text { intermediação }\end{array}$ & 79 & 96 & 57 & 31 & 113 & 103 & 100 & 91 & 94 & 96 & 113 & 94 & 15 & 37 & 57 \\
\hline
\end{tabular}

\subsection{Funcionários Mais Influentes}

A partir dos resultados fornecidos pelo software ORA formamos a TAB. 7 para nos ajudar a perceber quem seriam os atores mais influentes. Vamos adotar os seguintes critérios: (a) incluir os mais bem ranqueados cuja soma das ocorrências atinja ou ultrapasse $50 \%$ e (b) cortar em um ponto em que haja uma diferença significativa entre o último incluído e o primeiro excluído. Com tais critérios são cinco os atores mais importantes, ou seja, os funcionários de código de identificação 113, 57, 31, 94 e 100.

TABELA 7 -Ranking dos funcionários mais influentes na rede de influencia de cultura de segurança

\begin{tabular}{ccccc}
\hline \multicolumn{5}{c}{ Ranking da Multirede } \\
\hline Pos. & Id. Funcionário & Ocorrências & Ocorrências (\%) & Acumulado (\%) \\
\hline 1 & 113 & 11 & $18,33 \%$ & $18,33 \%$ \\
\hline 2 & 57 & 7 & $11,67 \%$ & $30,00 \%$ \\
\hline 3 & 31 & 6 & $10,00 \%$ & $40,00 \%$ \\
\hline 4 & 94 & 5 & $8,33 \%$ & $48,33 \%$ \\
\hline 5 & 100 & 4 & $6,67 \%$ & $55,00 \%$ \\
\hline 6 & 5 & 3 & $5,00 \%$ & $60,00 \%$ \\
\hline 7 & 9 & 3 & $5,00 \%$ & $65,00 \%$ \\
\hline 8 & 15 & 3 & $5,00 \%$ & $70,00 \%$ \\
\hline 9 & 79 & 3 & $5,00 \%$ & $75,00 \%$ \\
\hline 10 & 96 & 3 & $5,00 \%$ & $80,00 \%$ \\
\hline 11 & 103 & 2 & $3,33 \%$ & $83,33 \%$ \\
\hline
\end{tabular}




\begin{tabular}{lcccc}
12 & 104 & 2 & $3,33 \%$ & $86,67 \%$ \\
\hline 13 & 37 & 1 & $1,67 \%$ & $88,33 \%$ \\
\hline 14 & 42 & 1 & $1,67 \%$ & $90,00 \%$ \\
\hline 15 & 52 & 1 & $1,67 \%$ & $91,67 \%$ \\
\hline 16 & 59 & 1 & $1,67 \%$ & $93,33 \%$ \\
\hline 17 & 78 & 1 & $1,67 \%$ & $95,00 \%$ \\
\hline 18 & 91 & 1 & $1,67 \%$ & $96,67 \%$ \\
\hline 19 & 99 & 1 & $1,67 \%$ & $98,33 \%$ \\
\hline 20 & 166 & 1 & $1,67 \%$ & $100,00 \%$ \\
\hline
\end{tabular}

\subsection{Analisando Resultados de Cada Rede}

\subsubsection{Visão de Segurança(VS)}

Antes de comentarmos a análise da rede em si, é necessário discutir o significado desta rede. Observemos as 2 perguntas que davam origem ao mapeamento desta rede.

a) Ao observar seus colegas no dia a dia do trabalho, cite aqueles que, na sua percepção, melhor tipificam uma correta visão de segurança em seus atos, atitudes, e opiniões.

b) Considerando o seu dia a dia de trabalho, liste as pessoas a quem você costuma recorrer quando tem uma dúvida em assunto relacionado à segurança.

Considere a figura 2, a seguir, quando o indivíduo 1 indica 0 indivíduo 2 na questão a, ele está informando que 2 é um modelo para ele no tocante a atos, atitudes e opiniões relativas à segurança. Se também na questão $\boldsymbol{b}$ houver a mesma indicação, então além da consideração e observação de 2 como modelo, o 1 também toma a iniciativa de consultar o 
2 sempre que ele tem dúvidas relacionadas à segurança (figura 2). Neste caso a influência esperada de 2 sobre 1 é bastante grande para a disseminação, aprimoramento ou consolidação de conceitos, valores e atitudes relativos à cultura de segurança.

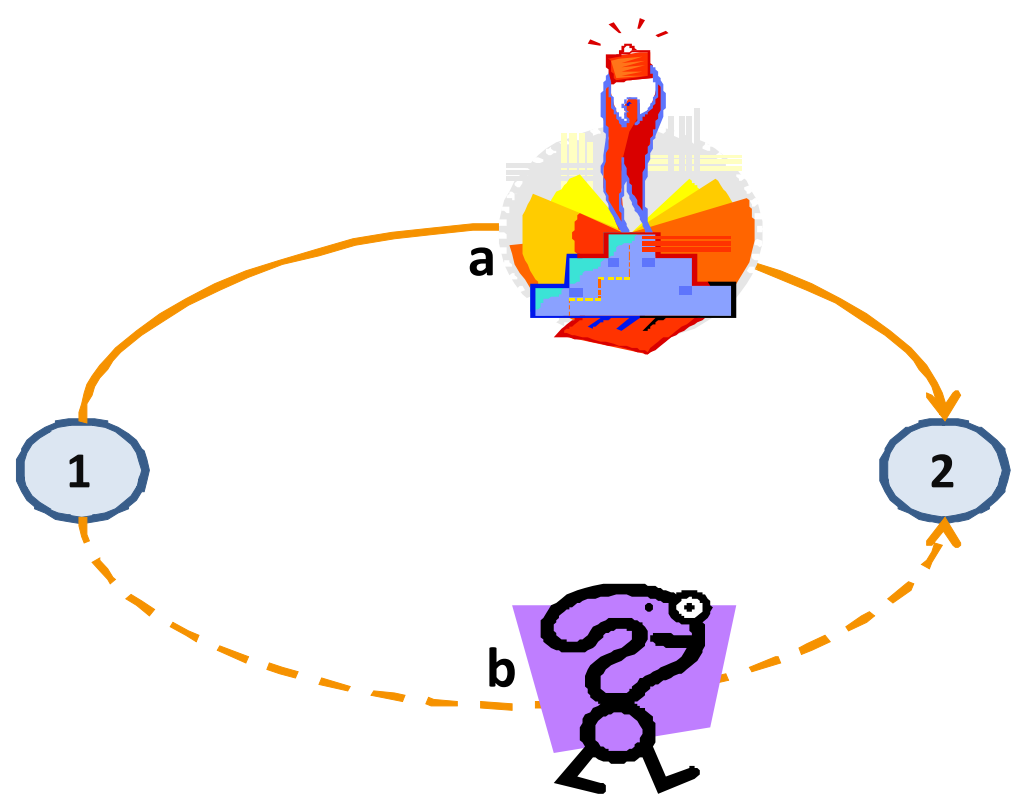

Figura 2 - Significado da rede visão de segurança do ponto de vista do respondente Observe, no entanto, que ao incluir estas informações na rede nós temos que mudar o sentido (da seta) do arco, pois na rede nós queremos representar o sentido do fluxo de influência (figura 3) 


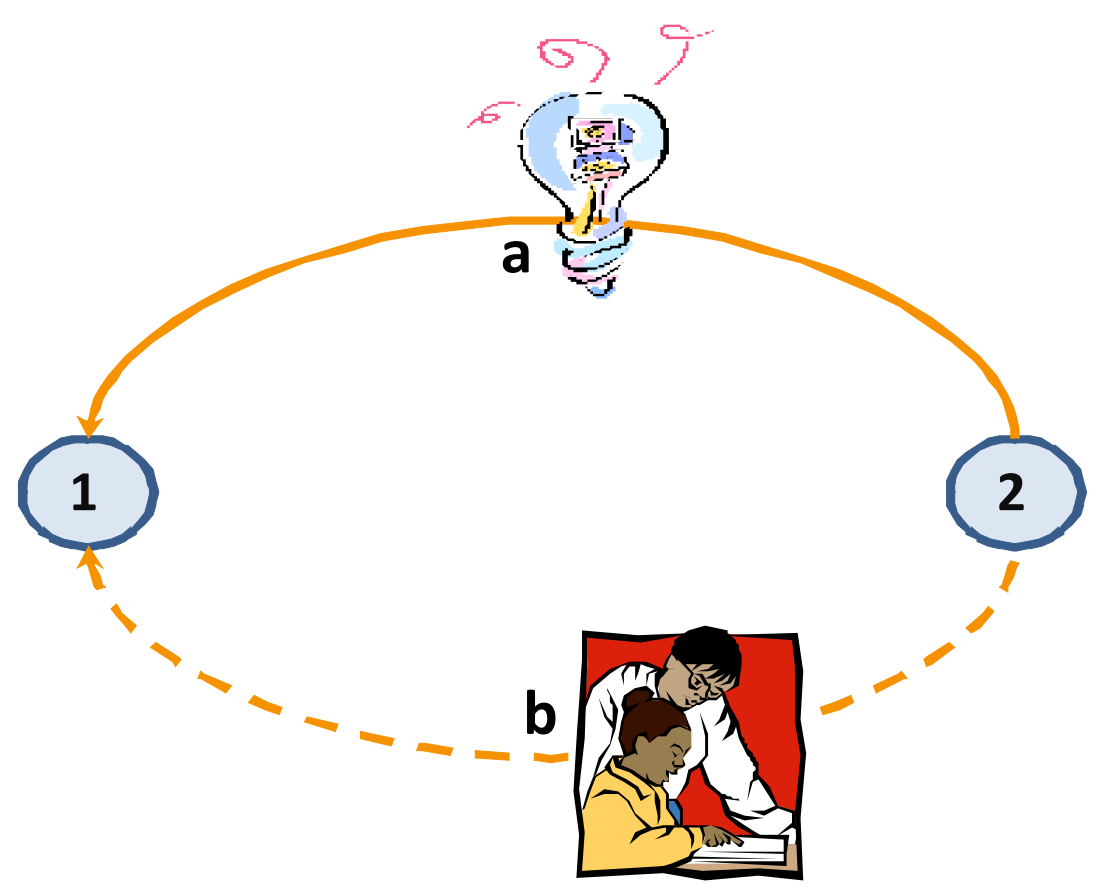

Figura 3 - Significado da rede visão de segurança do ponto de vista do fluxo de influência

À figura 3, podemos interpretar que a o laço a seria que o indivíduo 2 é inspiração, ou um modelo de comportamento para o indivíduo 1. Já o laço $\boldsymbol{b}$ diz que o indivíduo 2 é fonte de esclarecimento de dúvidas para o 1.

Note que como nós retemos todas estas informações em nosso modelo nós podemos tratar os laços da rede de forma ponderada ( $\boldsymbol{a}$ e $\boldsymbol{b}$ ), ou considerar apenas os relacionamentos que tenham $\boldsymbol{a}$ e $\boldsymbol{b}$, ou ainda tratá-los como redes separadas das relações definidas por $\boldsymbol{a}$ e $\boldsymbol{b}$.

Nesta dissertação não haverá tempo para analisar e comparar os resultados com todas estas várias alternativas de análise, mas as vertentes principais serão analisadas.

Após discutirmos o significado das outras redes, ficará evidente que a rede visão de segurança é a mais importante para os propósitos de utilização dos resultados desta análise no aprimoramento da cultura de segurança. 


\subsubsection{Análise da rede VS como um todo}

$\mathrm{Na}$ figura 4 vemos a rede original, com 2 nós isolados, 8 pendentes e um núcleo razoavelmente denso. Interessante observar que são 3 os pendentes que influenciam e 5 que são influenciados.

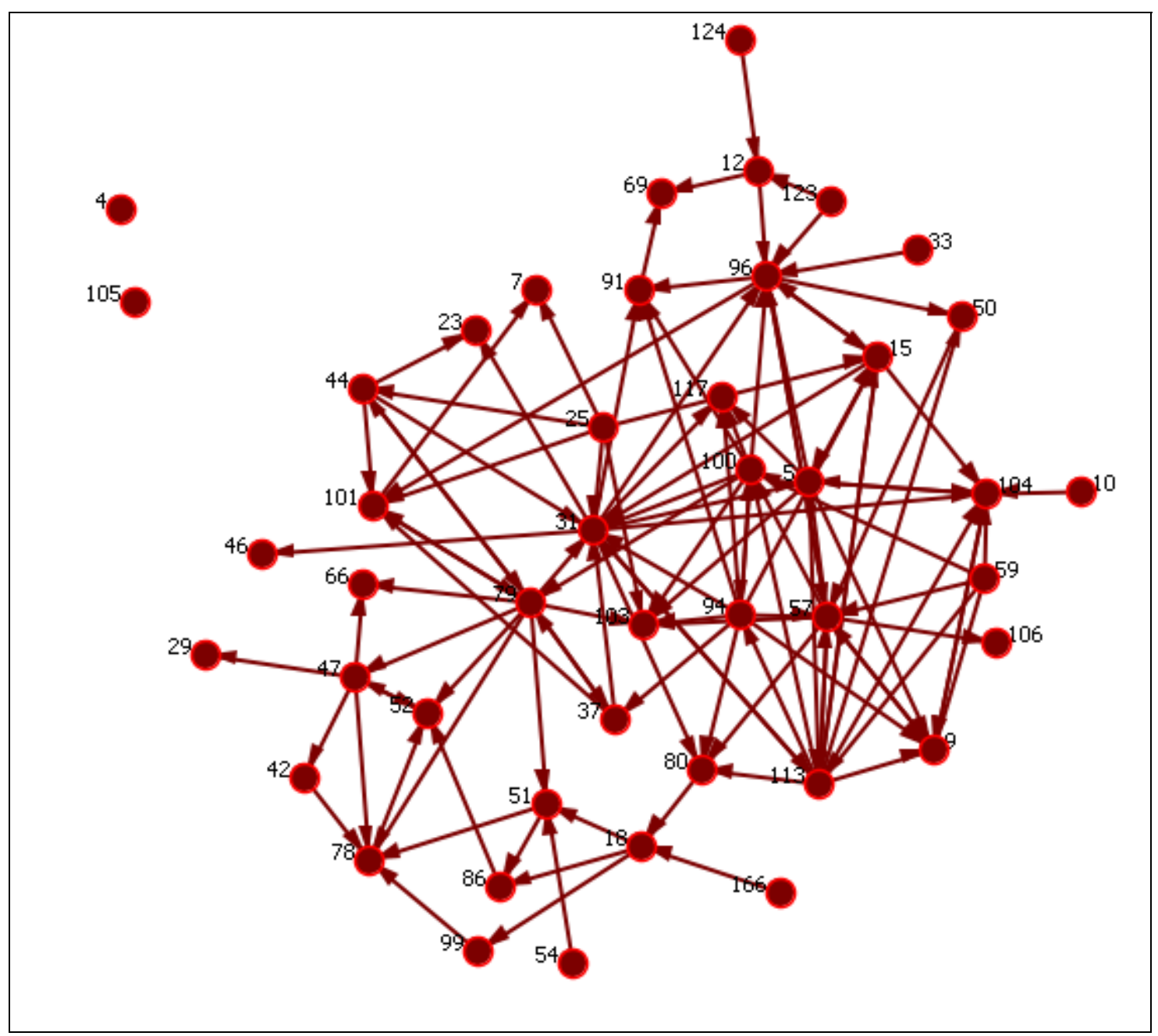

Figura 4 - Rede Visão de Segurança Original

A seguir, na figura 5, mostramos a rede reduzida, ou seja, sem os isolados e pendentes e desta forma pudemos destacar um pouco mais os nós de forma a facilitar a visualização daqueles com mais conexões. 


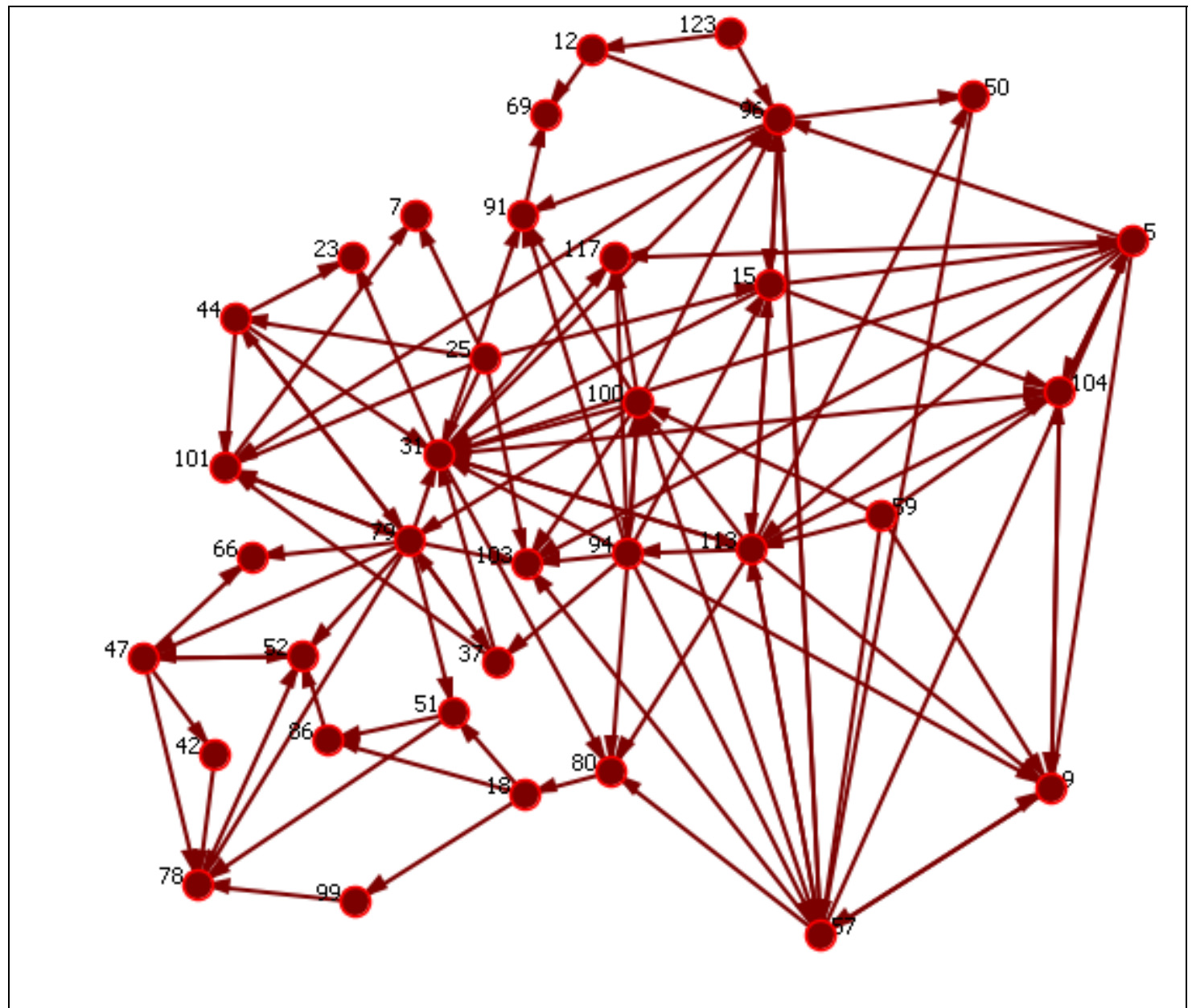

Figura 5 - Rede Visão de Segurança Reduzida

A TAB. 8 resume informações sobre a rede em questão. A rede original tem cerca de $10 \%$ de seus atores (isolados e pendentes) que teriam baixa ou nenhuma importância na conformação da cultura de segurança da população pesquisada. Por outro lado a rede reduzida é bastante robusta, por exemplo, não há nenhum nó que se fosse retirado fragmentaria a rede. A rede também apresenta um índice de reciprocidade razoável, o que aumenta a redundância de caminhos para se alcançar um dado nó. Além disto, a distância média é razoavelmente pequena.

Uma configuração como esta facilita uma intervenção de fortalecimento da cultura de segurança. Suponha que a organização queira introduzir novos valores, atitudes ou comportamentos, se for feito um convencimento dos atores mais centrais e eles adotarem tais mudanças, elas tenderão a se disseminar com certa facilidade. 
TABELA 8 - Características e Indicadores da Rede Visão de Segurança

\begin{tabular}{lcc}
\hline & \multicolumn{2}{c}{ Rede Visão Segurança } \\
\hline & Original & Reduzida \\
\hline $\mathrm{N}^{\circ}$ de Nós & 45 & 35 \\
\hline $\mathrm{N}^{\circ}$ de Ligações & 120 & 112 \\
\hline $\mathrm{N}^{\circ}$ de Componentes & $3(2$ Isolados) & 1 \\
\hline $\mathrm{N}^{\circ}$ Pendentes & 8 & 0 \\
\hline Fragmentação & 0,0879 & 0 \\
\hline Densidade & 0,0606 & 0,09 \\
\hline Reciprocidade & $12 \%$ & $13 \%$ \\
\hline Distância Média & 2,8276 & 2,57 \\
\hline Boundary spanners (quant.) & 8 & 0 \\
\hline
\end{tabular}

\subsubsection{Funcionários mais influentes da rede Visão de Segurança}

Seguindo os mesmos critérios usados na seção anterior, observamos que os atores 31, 57, 113 e 94 nitidamente se destacam dos demais. Os quatro em conjunto concentram 75\% das incidências entre os 5 primeiros colocados para os quatro indicadores considerados, conforme demonstrado à TAB. 9. 
TABELA 9 -Ranking dos funcionários mais influentes na rede Visão de Segurança

\begin{tabular}{cccc}
\hline \multicolumn{4}{c}{ Rede VISÃO de SEGURANÇA } \\
\hline Pos. & $\begin{array}{c}\text { Id. } \\
\text { Funcionário }\end{array}$ & Ocorrências & $\begin{array}{c}\text { Percentual de } \\
\text { Ocorrências }\end{array}$ \\
\hline 1 & 31 & 4 & $20,00 \%$ \\
\hline 2 & 57 & 4 & $20,00 \%$ \\
\hline 3 & 113 & 4 & $20,00 \%$ \\
\hline 4 & 94 & 3 & $15,00 \%$ \\
\hline 5 & 96 & 2 & $10,00 \%$ \\
\hline 6 & 100 & 1 & $5,00 \%$ \\
\hline 7 & 166 & 1 & $5,00 \%$ \\
\hline 8 & 79 & 1 & $5,00 \%$ \\
\hline
\end{tabular}

Como era de se esperar esta classificação não muda quando analisamos a rede reduzida.

\subsubsection{Abertura e Comunicação (AC)}

O significado das ligações desta rede, que foi buscado com as duas questões feitas, é comentado com auxílio da figura 6. 


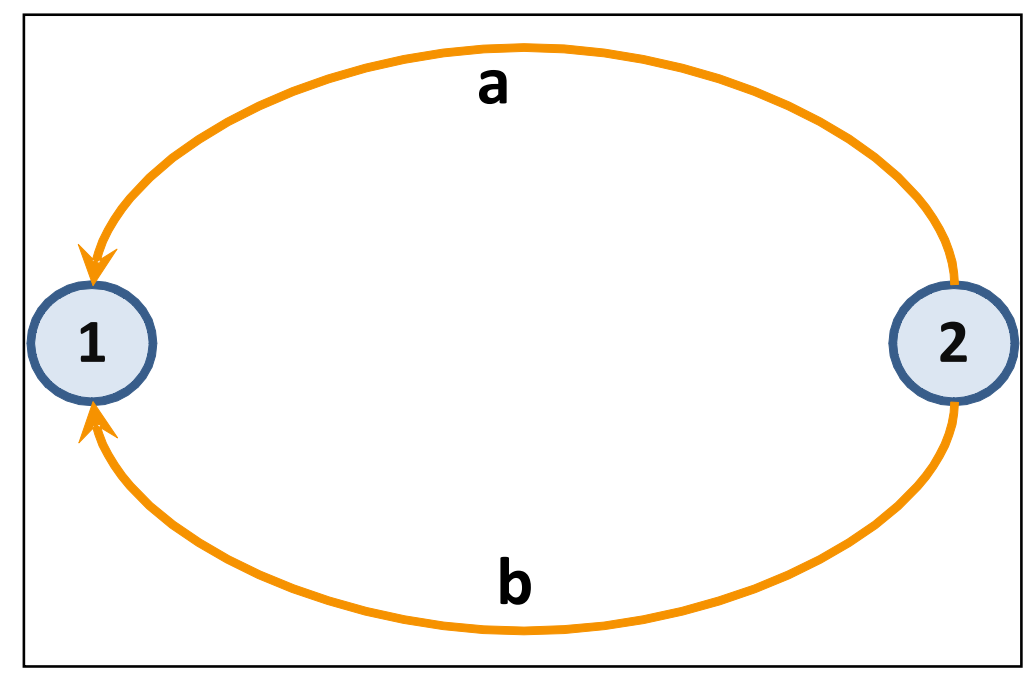

Figura 6- Significado dos arcos na rede de abertura e comunicação

A ligação a representa a grande capacidade de comunicação direta (facilidade de expressão, lucidez na exposição de idéias etc) que o ator 2 percebe no ator 1 . A ligação $\boldsymbol{b}$ representa a capacidade de comunicação indireta, ou seja, o ator 1 percebe o 2 como sendo uma pessoa importante na criação (ou aperfeiçoamento) de sistemáticas e canais de comunicação.

Podemos observar que, a ligação do tipo a é certamente mais relevante para indicar influência do ator 2 sobre o 1 . A ligação do tipo $\boldsymbol{b}$ não acrescenta quase nada como influência, pois o fato de 2 ser reconhecido como criador/aperfeiçoador de sistemáticas de comunicação não significa que ele se comunique eficazmente com o ator 1 . Infelizmente a rede foi computada considerando a união (dicotomizada) do conjunto de ambas relações. Futuramente isto será revisto.

A rede em questão, embora tenha o mesmo índice de fragmentação que a rede VS é menos densa e tem uma distância média maior, conforme é indicado na TAB. 10. 
TABELA 10 - Características e Indicadores da Rede Abertura e Comunicação

\begin{tabular}{lc}
\hline \multicolumn{2}{c}{ Comunicação } \\
\hline$N^{\circ}$ de Nós & 45 \\
\hline $\mathrm{N}^{\circ}$ de Ligações & 89 \\
\hline $\mathrm{N}^{\circ}$ de Componentes & $\mathbf{3}$ \\
\hline $\mathrm{N}^{\circ}$ de Nós Isolados & 2 \\
\hline Fragmentação & 0.0879 \\
\hline Densidade & 0.0449 \\
\hline Reciprocidade & $8 \%$ \\
\hline Distância Média & 3.7196 \\
\hline
\end{tabular}

\subsubsection{Funcionários mais influentes da rede Abertura e Comunicação}

$$
\text { Conforme demonstrado na TAB. 11, cinco são os atores mais }
$$
influentes 100, 113, 31, 79 e 103 que concentram 60\% das incidências. 
TABELA 11 - Ranking dos funcionários mais influentes na rede Abertura e Comunicação

\begin{tabular}{cccc}
\hline \multicolumn{4}{c}{ Rede ABERTURA e COMUNICAÇÃO } \\
\hline Pos. & Id. Funcionário & Ocorrências & Ocorrências (\%) \\
\hline 1 & 100 & 3 & $15,00 \%$ \\
\hline 2 & 113 & 3 & $15,00 \%$ \\
\hline 3 & 31 & 2 & $10,00 \%$ \\
\hline 4 & 79 & 2 & $10,00 \%$ \\
\hline 5 & 103 & 2 & $10,00 \%$ \\
\hline 6 & 5 & 1 & $5,00 \%$ \\
\hline 7 & 42 & 1 & $5,00 \%$ \\
\hline 8 & 52 & 1 & $5,00 \%$ \\
\hline 9 & 57 & 1 & $5,00 \%$ \\
\hline 10 & 91 & 1 & $5,00 \%$ \\
\hline 11 & 94 & 1 & $5,00 \%$ \\
\hline 12 & 99 & 1 & $5,00 \%$ \\
\hline
\end{tabular}

\subsubsection{Trabalho em Equipe(TE)}

Para levantamento desta rede, tivemos como base duas questões, que foram agrupadas na dimensão "colaboração e trabalho em equipe" do questionário para levantamento de redes. A figura 7 nos ajudará explicar esta relação.

A primeira questão deste grupo procurou identificar os destaques, para o ator 2, quanto ao trabalho em equipe. A relação a identifica que o ator 2 considera que o ator 1 é destaque no quesito "trabalho em grupo". A segunda questão explora uma relação de composição de equipe, no qual o ator 2 participou, em um passado recente e o ator 1 também tenha participado. A relação $b$ identifica que o ator 2 compôs equipe com o ator 1 . É importante observar que, para que a relação a aconteça, não necessariamente a relação $\boldsymbol{b}$ deva existir. 


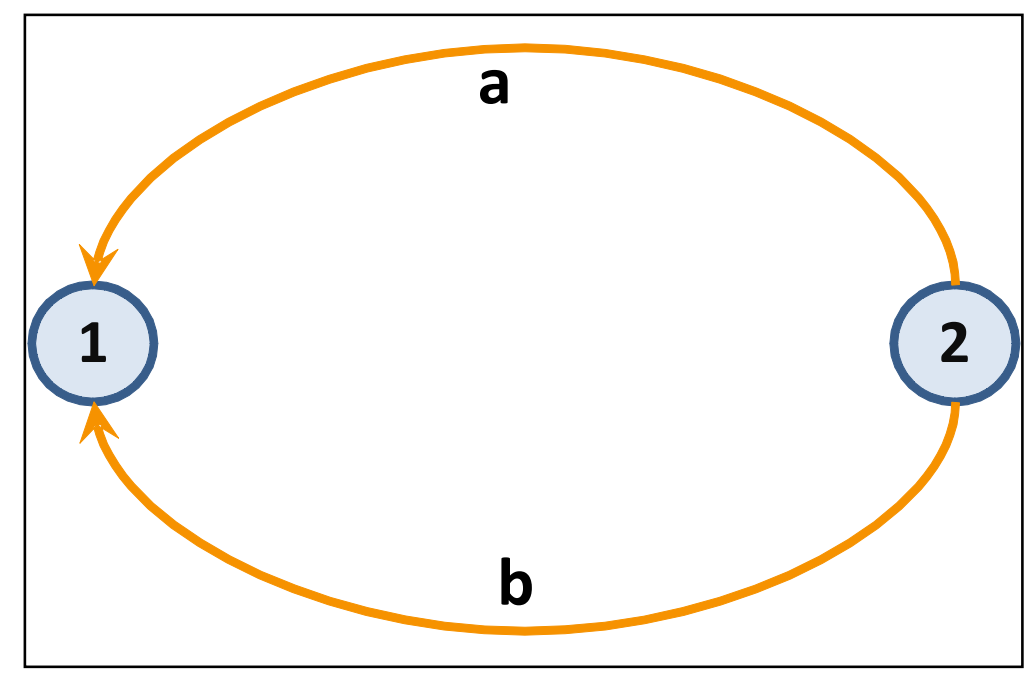

Figura 7 - Significado dos arcos da rede Trabalho em Equipe

Observamos à TAB. 12 o comportamento da rede TE, podemos notar que esta rede é menos densa que a rede VS, porém este índice é próximo do índice da rede $A C$. Já o índice de reciprocidade desta rede está mais próxima da rede VS e mais distante da rede AC. Este mesmo comportamento, podemos observar no número de ligações.

TABELA 12 - Características e Indicadores da Rede Trabalho em Equipe Trabalho em Equipe

\begin{tabular}{lc}
\hline $\mathrm{N}^{\circ}$ de Nós & 45 \\
\hline $\mathrm{N}^{\circ}$ de Ligações & 94 \\
\hline $\mathrm{N}^{\circ}$ de Componentes & $\mathbf{3}$ \\
\hline $\mathrm{N}^{\circ}$ de Nós Isolados & $\mathbf{2}$ \\
\hline Fragmentação & 0.0879 \\
\hline Densidade & 0.0475 \\
\hline Reciprocidade & $14 \%$ \\
\hline Distância Média & 3.0884 \\
\hline
\end{tabular}




\subsubsection{Funcionários mais influentes da rede Trabalho em Equipe}

Já nesta rede, seguindo os mesmos critérios apenas 3 atores são os mais influentes, quais sejam: 113, 9 e 15, demonstrados à TAB. 13.

TABELA 13 - Ranking dos funcionários mais influentes na rede Trabalho em Equipe

\begin{tabular}{cccc}
\hline \multicolumn{5}{c}{ Rede TRABALHO EM EQUIPE } \\
\hline Pos. & Id. Funcionário & Ocorrências & Ocorrências (\%) \\
\hline 1 & 113 & 4 & $20,00 \%$ \\
\hline 2 & 9 & 3 & $15,00 \%$ \\
\hline 3 & 15 & 3 & $15,00 \%$ \\
\hline 4 & 5 & 2 & $10,00 \%$ \\
\hline 5 & 57 & 2 & $10,00 \%$ \\
\hline 6 & 104 & 2 & $10,00 \%$ \\
\hline 7 & 37 & 1 & $5,00 \%$ \\
\hline 8 & 59 & 1 & $5,00 \%$ \\
\hline 9 & 78 & 1 & $5,00 \%$ \\
\hline 10 & 94 & 1 & $5,00 \%$ \\
\hline
\end{tabular}

\subsubsection{Rede Aprendizagem Organizacional(AO)}

A figura 8 mostra uma rede fragmentada e, se compararmos os índices desta rede com as demais, perceberemos que esta tem baixa densidade e alta fragmentação em relação às outras redes. Portanto, as influências desta rede terá pouca representação na cultura de segurança. Desta forma esta rede deve ser excluída da composição da rede agregada, pois só irá reduzir o poder explicativo da influência dos atores mais destacados. 


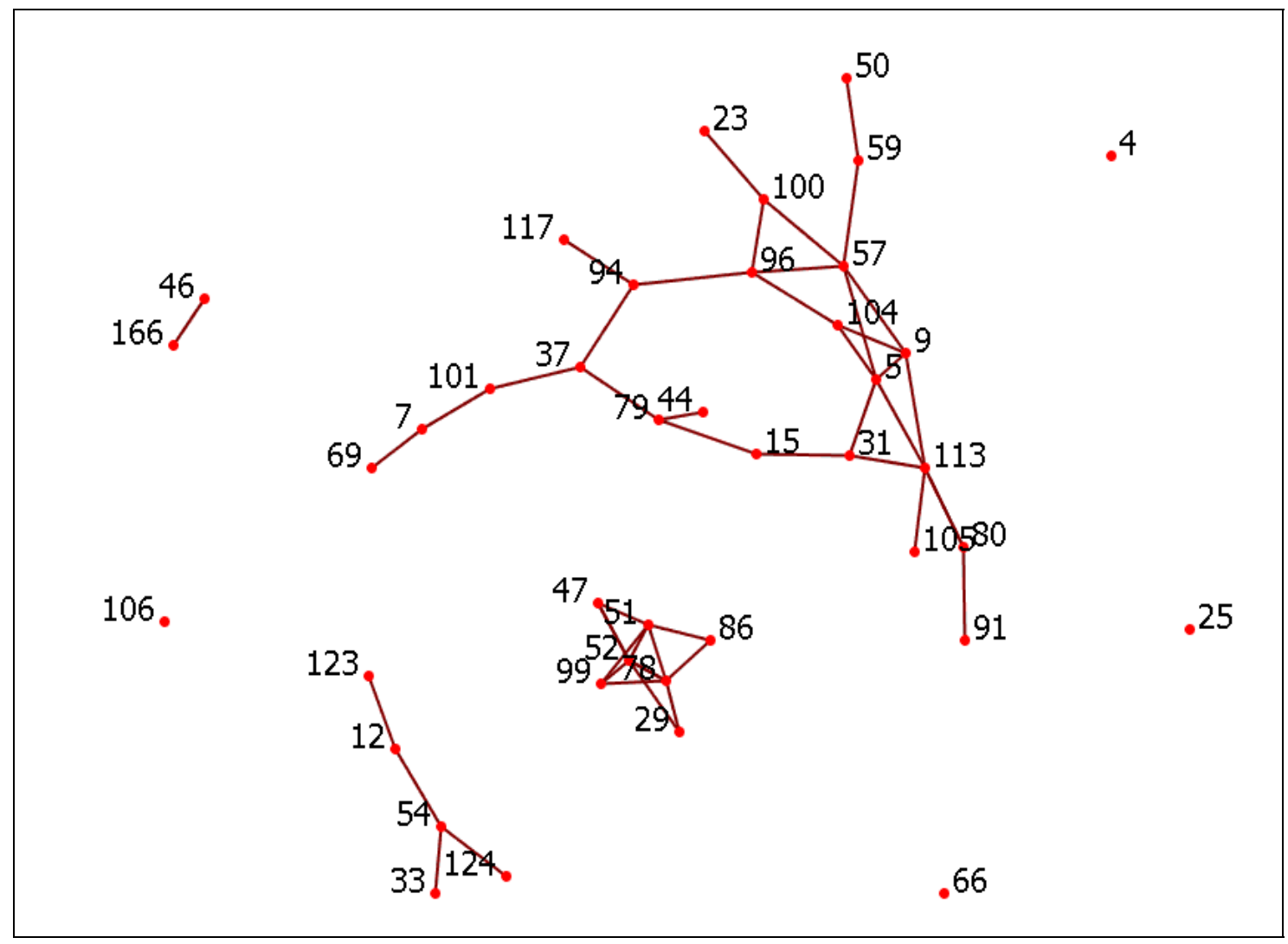

Figura 8 - Rede de influências de cultura de segurança dos funcionários do IPEN-CNEN-SP Aprendizagem Organizacional"

Também podemos observar à TAB. 14 que há uma grande quantidade de atores isolados, bem como elevado número de componentes.

TABELA 14 -Características e Indicadores da Rede Aprendizagem Organizacional

\begin{tabular}{lc}
\multicolumn{2}{c}{ Aprendizagem Organizacional } \\
\hline $\mathrm{N}^{\circ}$ de Nós & 45 \\
\hline $\mathrm{N}^{\circ}$ de Ligações & 49 \\
\hline $\mathrm{N}^{\circ}$ de Componentes & 9 \\
\hline $\mathrm{N}^{\circ}$ de Nós Isolados & 6 \\
\hline Fragmentação & 0.5384 \\
\hline Densidade & 0.0283 \\
\hline Reciprocidade & $5 \%$ \\
\hline Distância Média & 1.8433 \\
\hline
\end{tabular}




\subsubsection{Resumo Conclusivo da Análise das Redes}

Na TAB. 15 é apresentado um resumo dos principais indicadores de todas as redes de forma que, com esta visão do conjunto, fique mais fácil fazer uma análise global e comparativa entre as redes.

A rede $V S$ á e mais importante pela natureza das relações que ela envolve, conforme já foi discutido na seção 4.5.1. Além disso ela é a mais robusta das redes individuais como mostram seus índices de densidade, fragmentação, reciprocidade e distância média. A seguir temos as redes AC e TE com índices próximos, mas com ligeira vantagem para a última. Por outro lado a natureza da relação a (capacidade de comunicação direta) da rede $A C$ é um pouco mais relevante que a da rede TE.

TABELA 15 -Quadro Resumo das Redes

\begin{tabular}{|c|c|c|c|c|c|}
\hline Indicadores & Multirede & VS & $A C$ & TE & $\mathrm{AO}$ \\
\hline & $(V S+A C+T E+A O)$ & & & & \\
\hline Nº de Nós & 45 & 45 & 45 & 45 & 45 \\
\hline$N^{\circ}$ de Ligações & 211 * & 120 & 84 & 94 & 49 \\
\hline $\begin{array}{l}\mathrm{N}^{\circ} \text { de } \\
\text { Componentes }\end{array}$ & 1 & $\begin{array}{c}3(2 \\
\text { isolados) }\end{array}$ & $\begin{array}{c}3(2 \\
\text { isolados) }\end{array}$ & $\begin{array}{c}3(2 \\
\text { isolados) }\end{array}$ & $\begin{array}{c}9(6 \\
\text { isolados) }\end{array}$ \\
\hline $\mathrm{N}^{\circ}$ Pendentes & 0 & 8 & 8 & 8 & 10 \\
\hline Fragmentação & 0 & 0,0879 & 0,0879 & 0,0879 & 0,5384 \\
\hline Densidade & 0,11 & 0,0606 & 0,0449 & 0,0475 & 0,0283 \\
\hline Reciprocidade & $25 \%$ & $12 \%$ & $8 \%$ & $14 \%$ & $5 \%$ \\
\hline Distância Média & 2,45 & 2,8276 & 3,7196 & 3,0884 & 1,8433 ** \\
\hline $\begin{array}{l}\text { Boundary } \\
\text { spanners(qtd) }\end{array}$ & 0 & 8 & 8 & 8 & 10 \\
\hline $\begin{array}{l}\text { Atores mais } \\
\text { influents }\end{array}$ & 113 & 31 & 100 & 113 & irrelevante \\
\hline $\begin{array}{l}\text { Atores mais } \\
\text { influents }\end{array}$ & 57 & 57 & 113 & 9 & irrelevante \\
\hline $\begin{array}{l}\text { Atores mais } \\
\text { influents }\end{array}$ & 31 & 113 & 31 & 15 & irrelevante \\
\hline $\begin{array}{l}\text { Atores mais } \\
\text { influents }\end{array}$ & 94 & 94 & 79 & & $\ldots$ \\
\hline $\begin{array}{l}\text { Atores mais } \\
\text { influents }\end{array}$ & 100 & & 103 & & \\
\hline & & & & & \\
\hline
\end{tabular}


A discussão sobre a importância das ligações representadas em cada rede é qualitativa e deve ser qualificada e contextualizada de acordo com o propósito da análise. O uso mais nobre do presente estudo é dar subsídios para que possa da forma mais eficaz melhorar a cultura de segurança da organização analisada. Neste contexto, vejamos que relações indicativas de influência entre pessoas são as mais importantes.

A seguir alinharemos alguns argumentos para qualificar esta importância:

1. Se você considera uma determinada pessoa como modelo de visão de segurança em termos de atos, atitudes e opiniões, então esta pessoa tem um grande potencial para Ihe influenciar em assuntos desta natureza;

2. Se além disso, esta pessoa é uma das que você procura quando tem dúvidas relacionadas à segurança, então além de potencial ela tem muitas oportunidades para lhe influenciar;

3. Se esta pessoa tem grande capacidade / facilidade de comunicação direta, então esta pessoa deverá ser efetiva nas oportunidades que tiver de lhe influenciar;

4. Se você considera uma pessoa como sendo hábil na criação (ou aperfeiçoamento) de sistemáticas e canais de comunicação, então ela pode ser útil à organização neste sentido, mas não é por esta qualidade que ela terá qualquer influência sobre você em assunto de segurança; 
5. Se você considera que uma pessoa é muito hábil e sinergética para trabalho em equipe, pois ela anima o grupo, é pró-ativa, gerencia eventuais conflitos e consegue com que todos dêem o melhor de si, isto não significa que esta pessoa vá influenciar suas opiniões. Por outro lado ela vai facilitar a obtenção de consenso e se houver no grupo pessoas que tenham a possibilidade de Ihe influenciar esta possibilidade será amplificada. Nas atividades em grupo de programas de fortalecimento da cultura de segurança é importante que pessoas deste tipo estejam presentes em todos os grupos;

6. Se além de manifestar a opinião do item anterior sobre determinada pessoa, você indicou que no último ano participou em algum trabalho de grupo com ela, isto reforça a credibilidade da opinião anterior, pois esta é uma qualidade que as pessoas podem aprimorar ou retroceder com o tempo.

Observe que os argumentos de 1 e 2 referem-se às relações a e $\boldsymbol{b}$ da rede VS; os de 3 e4 referem-se às relações $\mathbf{a}$ e $b$ da rede $A C$; e os de 5 e 6 referem-se às relações $\boldsymbol{a}$ e $\boldsymbol{b}$ da rede TE. A partir do exposto as seguintes conjecturas são muito plausíveis:

- Em qualquer programa visando uma melhoria na cultura de segurança as pessoas que são os multiplicadores mais eficazes são aquelas de maior centralidade em uma rede ponderada que incluísse as relações $\boldsymbol{a}$ e $\boldsymbol{b}$ de VS e a relação $\boldsymbol{a}$ de AC. Também seriam estas pessoas cujo vetor cultural teria maior poder explicativo da distribuição dos vetores da população, análise que podemos observar à seção 4.5.7. Alternativamente usaríamos os 
atores mais centrais da rede $\mathbf{V S}$. Um acontecimento favorável foi o fato que todos atores mais centrais da rede $\boldsymbol{V} S$, bem como percebemos que 3 dos 5 da rede $A C$ aparecem como os mais importantes da multirede agregada (TAB. 15) e eles serão usados nas análises do item 4.5.7.

- Também nas ações do programa de melhoria da cultura de segurança que envolvam o desenvolvimento / aprimoramento dos sistemas e processos de comunicação, as pessoas de maior centralidade detectadas na rede que envolvesse as relações da rede $\boldsymbol{A C}$ com maior ponderação para a relação $\boldsymbol{b}$ devem ser envolvidas. Na forma em que as redes foram compiladas isto não dá para ser feito, mas valem aqui as mesmas observações feitas no item anterior.

- Programas de aprimoramento da cultura de segurança envolvem normalmente vários trabalhos em grupo e neste caso os atores mais importantes da rede $\boldsymbol{T E}$, com as ressalvas anteriores deverão ser distribuídos nos grupos.

\subsubsection{Análise de Caracterização da Cultura de Segurança}

A TAB. 16 mostra todos os vetores culturais dos 45 atores que satisfizeram aos critérios da pesquisa. A TAB. 16 tem 12 colunas: a primeira contém o ID do funcionário, que foi atribuído quando ele começou a participar no processo de pesquisa; as dez seguintes são as coordenadas do vetor, ou seja, a pontuação escolhida pelo respondente a cada uma das 10 questões em uma escala intervalar de 5 pontos, com elemento neutro (de -2 a +2). A última coluna é um escore agregado representativo do respondente. Este último índice é calculado como uma soma direta das respostas, posto que todas as perguntas admitiam respostas que refletiam tanto percepções / opiniões negativas ou positivas a respeito das assertivas que eram 
colocadas (detalhes no apêndice C). Desta forma este índice, que pode variar de -20 a +20 capta, no global, o quão positiva ou negativa é a percepção do respondente quanto às condições emblemáticas (variáveis amostráveis) da cultura de segurança. É importante observar que as questões foram feitas sempre em relação ao Centro a qual a pessoa pertence, este ponto será usado nos comentários de 4.5.7 também. 
TABELA 16 - Vetor cultural das redes de relacionamentos do IPEN-CNENSP

\begin{tabular}{|c|c|c|c|c|c|c|c|c|c|c|c|}
\hline ID & coordl & $\operatorname{coord} 2$ & coords & coord4 & $\operatorname{coord} 5$ & coords & coord? & coords & coords & coordlo & Escore \\
\hline 10 & -2 & -2 & -1 & -2 & -1 & 1 & -1 & -1 & -1 & -1 & -11 \\
\hline 103 & -1 & -1 & -2 & -1 & -1 & -1 & -2 & -1 & 0 & 1 & -9 \\
\hline 47 & -1 & 0 & 0 & -2 & 1 & -1 & -1 & -2 & 0 & -1 & -7 \\
\hline 18 & 1 & 1 & -1 & -2 & -1 & -1 & -2 & -2 & 0 & 1 & -6 \\
\hline 42 & 1 & 1 & 1 & -1 & 1 & -2 & -2 & -1 & -2 & -2 & -6 \\
\hline 51 & -1 & -1 & 0 & 0 & 0 & 0 & 0 & 0 & -2 & -1 & -5 \\
\hline 69 & -1 & -2 & -1 & -1 & -1 & -1 & 1 & 1 & 1 & 1 & -3 \\
\hline 94 & -1 & -1 & -1 & -1 & 0 & -1 & 1 & 1 & 1 & -1 & -3 \\
\hline 52 & 1 & -1 & 1 & 1 & 1 & -1 & 1 & -1 & -1 & -1 & 0 \\
\hline 29 & 1 & 2 & 1 & -1 & -1 & -1 & -1 & -1 & 1 & 1 & 1 \\
\hline 46 & 1 & 1 & -1 & -1 & 0 & 0 & 0 & 1 & -1 & 1 & 1 \\
\hline 23 & 1 & 2 & 1 & -1 & 0 & -1 & -1 & -1 & 1 & 1 & 2 \\
\hline 9 & -2 & 2 & 2 & -2 & 1 & 2 & 2 & -2 & 1 & 1 & 5 \\
\hline 166 & 0 & 1 & 0 & 1 & 0 & 0 & 1 & 1 & 1 & 1 & 6 \\
\hline 66 & -1 & 0 & 2 & -1 & 1 & 1 & 1 & 1 & 1 & 1 & 6 \\
\hline 37 & 1 & 2 & 1 & 1 & 1 & 0 & 0 & 1 & 1 & 0 & $\hat{8}$ \\
\hline 4 & 1 & 1 & 1 & 2 & 2 & 2 & 0 & 1 & -1 & 0 & 9 \\
\hline 100 & 1 & 1 & 1 & 1 & 1 & 1 & 1 & 1 & 1 & 0 & 9 \\
\hline 7 & 2 & 2 & 1 & 1 & 1 & 1 & -2 & 0 & 1 & 2 & 9 \\
\hline 105 & 1 & 1 & 0 & 2 & 2 & 1 & 0 & 0 & 1 & 2 & 10 \\
\hline 124 & 1 & 1 & 2 & 1 & 2 & 1 & 1 & 1 & -1 & 1 & 10 \\
\hline 15 & 1 & 1 & -1 & 1 & 1 & 1 & 2 & 2 & 1 & 2 & 11 \\
\hline 50 & 2 & 2 & 1 & 2 & -1 & 2 & 2 & -1 & 2 & 0 & 11 \\
\hline 57 & 1 & 1 & 1 & 2 & 1 & 1 & 2 & 1 & 1 & 0 & 11 \\
\hline 123 & 1 & 1 & 1 & 1 & 1 & 1 & 1 & 1 & 1 & 2 & 11 \\
\hline 5 & 1 & 2 & -1 & 1 & 1 & 2 & 2 & 1 & 1 & 2 & 12 \\
\hline 33 & -1 & 2 & 2 & 1 & 1 & 1 & 2 & 1 & 1 & 2 & 12 \\
\hline 12 & 1 & 2 & 1 & 1 & 2 & 1 & 2 & 0 & 1 & 2 & 13 \\
\hline 78 & 1 & 2 & 2 & 1 & 2 & 1 & 1 & 2 & 1 & 0 & 13 \\
\hline 104 & 1 & 2 & 1 & 1 & 1 & 2 & 2 & 1 & 1 & 1 & 13 \\
\hline 113 & 1 & 2 & 1 & 1 & 1 & 1 & 1 & 2 & 2 & 1 & 13 \\
\hline 91 & 1 & 1 & 1 & 1 & 2 & 1 & 2 & 1 & 2 & 2 & 14 \\
\hline 101 & 1 & 2 & 1 & 1 & 1 & 2 & 1 & 2 & 1 & 2 & 14 \\
\hline 31 & 2 & 2 & 1 & 1 & 2 & 1 & 2 & 2 & 1 & 1 & 15 \\
\hline 79 & 1 & 2 & 2 & 2 & 2 & 1 & 2 & 1 & 1 & 1 & 15 \\
\hline 25 & 2 & 2 & 2 & 2 & 2 & 2 & 1 & -1 & 2 & 2 & 16 \\
\hline 80 & 1 & 2 & 2 & 2 & 1 & 2 & 2 & 1 & 1 & 2 & 16 \\
\hline 54 & 2 & 2 & 2 & 1 & 2 & 2 & 1 & 1 & 2 & 2 & 17 \\
\hline 96 & 2 & 1 & 1 & 2 & 2 & 2 & 2 & 2 & 2 & 1 & 17 \\
\hline 44 & 2 & 1 & 1 & 2 & 2 & 2 & 2 & 2 & 2 & 2 & $1 \hat{8}$ \\
\hline 59 & 2 & 2 & 2 & 1 & 2 & 2 & 2 & 1 & 2 & 2 & 18 \\
\hline 106 & 1 & 2 & 2 & 2 & 2 & 2 & 1 & 2 & 2 & 2 & 18 \\
\hline 99 & 2 & 2 & 2 & 2 & 2 & 1 & 2 & 1 & 2 & 2 & 18 \\
\hline 86 & 2 & 2 & 2 & 2 & 2 & 2 & 2 & 2 & 1 & 2 & 19 \\
\hline 117 & 1 & 2 & 2 & 2 & 2 & 2 & 2 & 2 & 2 & 2 & 19 \\
\hline Méda & 0,76 & 1,16 & 0,84 & 0,64 & 1,00 & 0,82 & 0,84 & 0,58 & $0, \otimes 2$ & 0,98 & 8,44 \\
\hline
\end{tabular}


Na última linha estão as médias de cada coordenada, que constituem as coordenadas do centróide desta distribuição de vetores culturais neste hiper-espaço de 10 dimensões. A média dos escores dá uma idéia que a população tem uma percepção global razoavelmente positiva da cultura de segurança, embora com bastante espaço para melhorar. Esta análise poderia ser feita setorizada (por lotação), já que as perguntas referiam-se ao centro de cada um. Isto reduziria o poder estatístico de cada análise separada, mas daria boas indicações onde a cultura está mais fragilizada.

A figura 9 apresenta o escore dos pesquisados em ordem crescente. Pode ser observado que há uma ampla maioria com percepção positiva. Observando na TAB. 16, onde os atores mais centrais (identificados na coluna ID, com os números 94, 100, 57, 113 e 31) da multirede agregada, pode ser observado que 4 deles estão do lado positivo, acima da média, mas um deles está do lado negativo.

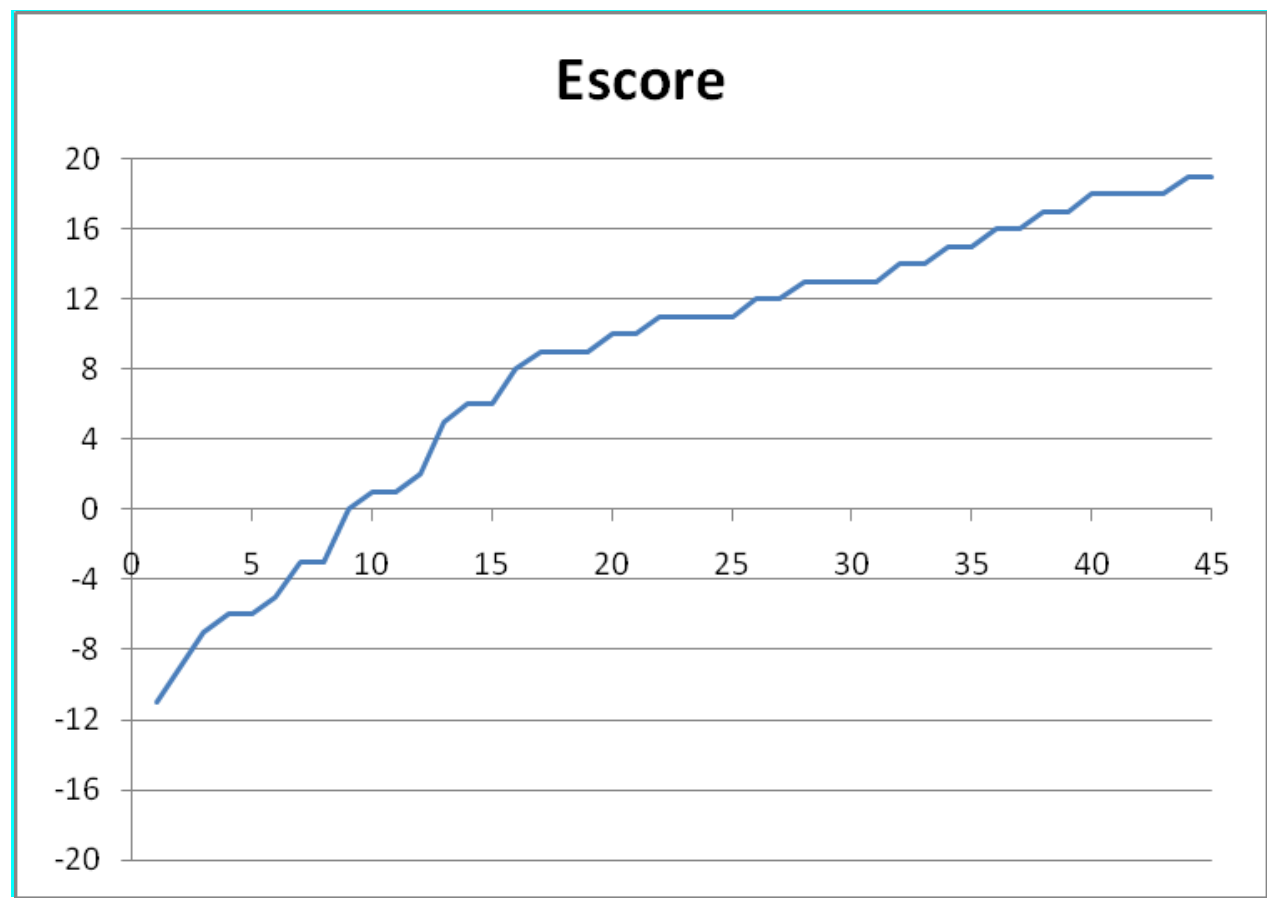

Figura 9 - Escore dos pesquisados, relativos ao vetor cultural 


\subsubsection{Análise Cruzada da Caracterização da Cultura de Segurança Com as Redes de Influências}

Há uma conjectura, mencionada em parte anteriormente, que se os atores mais centrais realmente influenciam os demais então deve haver alguma indicação disto que seja perceptível comparando os vetores culturais de influenciadores e influenciados. Há várias maneiras de testarmos esta conjectura, que se comprovada daria uma extraordinária validação à proposta de utilização dos resultados obtidos com a metodologia aqui descrita para desenhar programas de implantação ou melhoria de cultura de segurança de uma forma muito mais efetiva.

Serão feitas 2 análises conforme descrito a seguir:

a) A primeira consiste em comparar a média do escore da população com a média do escore dos 5 atores mais centrais da multi-rede agregada.

o A média dos escores do quinteto mais central é 9,00 e a média dos escores da "população" é 8,44;

- A seguir aplica-se um teste estatístico para verificar se a diferença entre estes 2 números é estatisticamente não significativa para a distribuição considerada;

b) O segundo é mais sofisticado e considera a distribuição dos 45 vetores no espaço decadimensional.

- As coordenadas do centróide da distribuição são usadas para fazer uma mudança de origem do referencial e todos os vetores passam a ser expressos no sistema centro 
de massa e suas distâncias euclidianas até o centróide são facilmente calculadas.

- Se os atores mais centrais são realmente influentes espera-se que a distância do centróide desta quíntupla até o centróide da "população" esteja aproximadamente no centro (média) da distribuição das distâncias de todas as quíntuplas que podem ser geradas por um processo de bootstraping a partir dos 45 vetores originais ("população"). Isto foi feito sendo geradas 1.221.759 quíntuplas, cuja distribuição é mostrada na figura 10. Nela podemos observar que se tivéssemos uma população suficientemente grande então era de se esperar que o posicionamento da quíntupla do mais "influentes" praticamente dividiria a distribuição ao meio.

o Caso a "população" fosse maior, por exemplo 200 vetores, era de se esperar que o centro da distribuição e a distância da quíntupla dos mais influentes tendesse a zero. Isto é eles ficassem quase que coincidentes com o centróide da população.

o Outra hipótese para que mesmo com uma população pequena, o efeito comentado acima pudesse acontecer seria no caso dos vetores culturais dos mais influentes apresentarem uma certa coerência, ou seja as questões avaliadas positivamente por um 
deles também o fossem pelos outros. Isto porem não ocorreu no nosso caso.

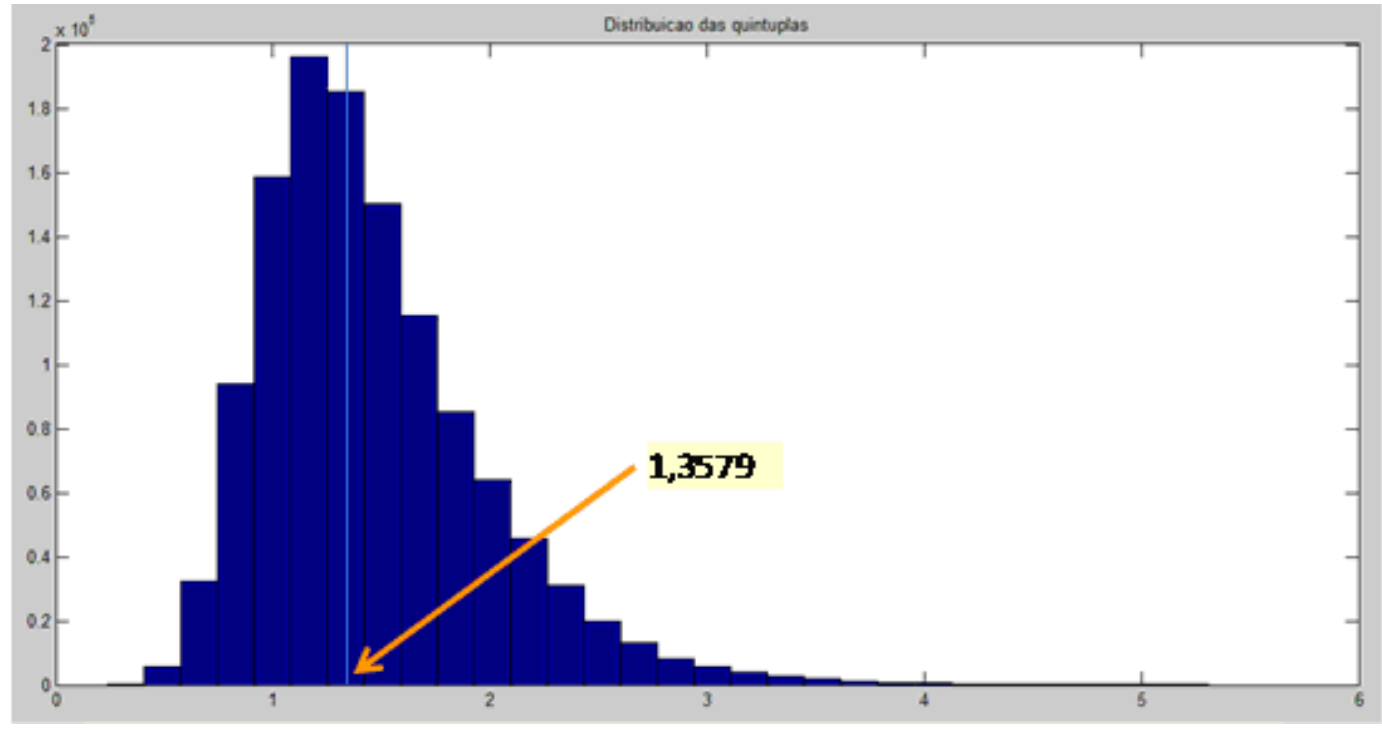

Figura 10 - Histograma da Distribuição de Quíntuplas e Posição da Quíntupla dos mais centrais 


\section{CONCLUSÕES}

Os resultados mostraram que a metodologia desenvolvida permite a identificação de redes sociais de influência que são muito relevantes na formação da cultura de segurança do IPEN-CNEN-SP. Além disto, a metodologia pode ser aplicada em qualquer organização. Como esta abordagem é inédita na literatura, houve bastante dificuldade de identificar quais seriam as questões mais adequadas para mapear tais redes. Utilizamos sete questões que foram grupadas dando origem a quatro redes e uma multirede geral que agrega todas as quatro. No decorrer do trabalho observamos que outras formas de configurar as redes poderiam ser mais eficazes ainda.

A identificação dos atores mais destacados (formadores de opinião e de comportamento) foi feita baseada nas várias redes, mas apenas os da multi-rede agregada foram usados para fazer a comprovação da influência. Outras vertentes de análise serão exploradas na sequência de outros trabalhos do grupo.

A análise cruzada dos vetores e redes permitiu demonstrar que realmente as redes levantadas captaram os atores mais influentes e que esta influência se reflete nos vetores que caracterizam a cultura da população. Isto dá muito estímulo e suporte para que este trabalho seja usado pelo IPEN em programas de aprimoramento de sua cultura de segurança. Neste sentido os comentários feitos em 4.5 .5 fornecem subsídios detalhados de como fazê-lo. 


\section{REFERÊNCIAS}

ACSNI(1993) ACSNI Human Factors Study Group. Third Report: Organising for Safety, Advisory Committee on the Safety of Nuclear Installations, Health and Safety Commission, HSE Books,1993.

Antonsen(2009) Antonsen S.,Safety culture: theory, method and improvement, Norwegian University of Science and Technology, ASHGATE, Norway,

Cheyne et al. (1998) Cheyne, A., Cox, S., Oliver, A., Tomas, J.M., Modelling safety climate in the prediction of levels of safety activity, Work and Stress 12 (3), 255-271

Cox and Flin(1998) Cox S., Flin R., Safety culture: Philosopher's stone or man of straw? Work \& Stress 12 (3):189-201.

Dawkins(1989) Dawkins R., The selfish gene, Oxford University Press

Deal e Kennedy(1982) Deal, T., Kennedy, A., Corporate Cultures. AddisonWesley, Reading, MA.

Emirbayer e Goodwin(1994) Emirbayer M, Goodwin J, Network Analysis, Culture, and the Problem of Agency, American Journal of Sociology, Vol. 99, No. 6, pp. 1411-1454.

Glendon e Stanton(2000) Glendon, A.I., Stanton, N.A., Perspectives on safety culture. Safety Science 34, 193-214.

Haukelid(2007) Haukelid K., Theories of (safety) culture revisited-An anthropological approach,Science Direct, Safety Sci. (2007), doi:10.1016/j.ssci.2007.05.014

Hendrick(1991) Hal W. Hendrick, Ergonomics in organizational design and management, Ergonomics, 1366-5847, Volume 34, Issue 6, 1991, Pages $743-756$

Hofstede(1990) Hofstede, G., Cultures and Organization: Software of the Mind. McGraw-Hill, London.

Hopkins(2006) Hopkins A., Studying Organisational Cultures and their Effects on Safety, Department of Sociology, in the Faculty of Arts, and 
National Research Centre for OHS Regulation, Australian National University, Australia

HSE(2001) Health \& Safety Climate Survey Tool - Process Guidelines, HSE Books, ISBN 071761462X HSE Books, UK

INSAG-4(1991) International Nuclear Safety Advisory Group, SAFETY CULTURE, IAEA Safety Series $n^{\circ}$ 75-INSAG-4,INTERNATIONAL ATOMIC ENERGY AGENCY, VIENNA, 1991

Kleinberg(1998) KLEINBERG, J.M. Authorithative sources in a hyperlinked environment. In.: ANNUAL ACM-SIAM SYMPOSIUM ON DISCRETE ALGORITHMS, 9., 1998. Proceedings... [s.l.:s.n.] 1998. Disponível em: http://citeseer.nj.nec.com/1115.html.

Mearns and Flin(1999); Mearns, K. J. and R. Flin. 1999. Assessing the state of organizational safety-Culture or climate? Current Psychology: Developmental, Learning, Personality, Social 18 (1): 5-17.

Nonaka e Takeuchi(1997) Nonaka, I.,Takeuchi, H.,Criação de Conhecimento na Empresa - Como as Empresas Japonesas Geram a Dinâmica da Inovação, Oxford University Press, US

Obadia(2004) Obadia I.J; Sistema de Gestão Adaptativo Para Organizações Com Tecnologia Perigosa: A Cultura de Segurança Como Pressuposto de Excelência Nuclear; Tese Universidade Federal do Rio de Janeiro-COPPE/UFRJ; Rio de Janeiro; 2004

Peters e Waterman(1982) Peters, T., Waterman, R., Search of Excellence. Harper \& Row, New York.

Pidgeon(1998) Pidgeon, N. 1998. Safety culture: Key theoretical issues. Work \& Stress 12 (3): 202-16.

Pousette(2006) Pousette A. Larsson S., Torner M., Safety climate crossvalidation, strength and prediction of safety behaviour,, Safety Sci. (2007), doi:10.1016/j.ssci.2007.06.016

Reason(1990) Reason, J.. Human error. New York, NY: Cambridge University Press.

Reason(1997) Reason J., Managing the Risks of Organizational Accidents. Ashgate, Alder shot

Richter e Koch(2004) Richter, A., Koch, C., Integration, differentiation and ambiguity in safety cultures. Safety Science 42, 703-722.

Rossoni e Guarido Filho (2007, p. 74) ROSSONI, L.; GUARIDO FILHO, E.R. 
Cooperação Interinstitucional no Campo da Pesquisa em Estratégia. Revista de Administração de Empresas, v. 47, n. 4, p. 74-88, 2007.

SCART(2008) INTERNATIONAL ATOMIC ENERGY AGENCY, SCART Guiderline - IAEA Safety Culture Assessment Review Team, Vienna,2008.

Schein(1992) Schein, E.H.Organizational Culture and Leadership, second ed. Jossey-Bass, San Francisco.

Scott(2000) SCOTT, J. Social Network Analysis: a handbook. 2 ed. London: Sage Publications, 2000.

Taylor(1924) Taylor E.B., Primitive Culture. 2 vols. 7th ed. New York: Brentano's.

TECDOC-1321(2002) INTERNATIONAL ATOMIC ENERGY AGENCY, SelfAssessment of Safety Culture in Nuclear Installations, Highlights and Good Practices, Vienna, 2002

TECDOC-1329(2002) INTERNATIONAL ATOMIC ENERGY AGENCY, Safety culture in nuclear installations: Guidance for use in the enhancement of safety culture, ISBN 92-0-119102-2, Vienna, 2002

Tharaldsen( 2007) Tharaldsen J.E., A longitudinal Study of safety climate on the Norwegian continental shelf, Science Direct, Safety Sci. (2007), doi:10.1016/j.ssci.2007.05.006

Wasserman e Faust(1994) Wasserman S., Faust K., Social Network Analysis: Methods and Applications. Cambridge University Press.

Wiegmann et al.(2002) Wiegmann, D. A., H. Zhang, T. L. von Thaden, G. Sharma, and A. A. Mitchell. 2002. A Synthesis of Safety Culture and Safety Climate Research. University of Illinois Aviation Research Lab Technical Report ARL-02-03/FAA-02-2.

Wiegmann(2007) Douglas A. Wiegmann and Terry L. von Thaden, A review of safety culture theory and its potential application to traffic safety, Institute of Aviation Human Factors Division, University of Illinois at UrbanaChampaign, Alyssa Mitchell Gibbons, Department of Psychology, University of Illinois at Urbana-Champaign 


\title{
ANEXO A - MODELO DE CARTA ENVIADA AOS GERENTES
}

\author{
IImo Sr. \\ Gerente do Centro XXXXXXXX,
}

Este trabalho visa mapear e entender as redes sociais que influenciam a formação e disseminação dos valores e pressupostos básicos das pessoas em relação à segurança em seu ambiente de trabalho. Instituições como o IPEN, ou qualquer outra organização, são entes sociais em as pessoas interagem formando diversas redes sociais informais por onde transitam informações, troca de conhecimento, discussão de idéias e consolidação de opiniões e padrões dominantes. Nosso interesse é mapear e entender a dinâmica daquelas redes que tenham relação com 0 conjunto de características e atitudes de "cultura de segurança" que queremos estudar. Uma vez concluído este trabalho trará significativos subsídios para políticas, treinamentos e ações de melhoria da cultura de segurança.

No primeiro momento queremos apenas identificar as pessoas que potencialmente podem colaborar nestas duas pesquisas. Para tanto estamos solicitando uma lista de pessoas que em sua visão representam são atores importantes na formação dos valores e pressupostos básicos relativos à segurança no contexto onde trabalham. Tal importância deve ser entendida de uma forma ampla, incluindo qualquer pessoa que atenda a um dos requisitos a seguir:

- Aqueles que por sua função têm que tomar decisões ou ações com possível impacto na segurança; 
- Aqueles que por seu conhecimento a respeito deste tema são consultados ou ouvidos com atenção sempre que manifestam sua opinião em assuntos de segurança; e

- Aqueles que por sua forma de agir sempre ciosos de manter um comportamento seguro em todas suas tarefas são assim reconhecidos por seus pares.

Tais pessoas receberiam um breve convite para participar de nosso estudo e, de acordo com o caso, poderiam ser entrevistadas ou receber um questionário para o mapeamento das redes. Obviamente a participação será feita em bases voluntárias.

Assim sendo, solicito a colaboração de V. Sa. em me enviar a lista de nomes das pessoas, de seu Centro, que atendam aos quesitos acima enunciados. 


\section{ANEXO B - QUESTIONÁRIO PARA LEVANTAMENTO DAS REDES}

\section{QUESTIONÁRIO}

\section{(1) Visão de segurança}

- Ao observar seus colegas no dia a dia do trabalho, cite aqueles que, na sua percepção, melhor tipificam uma correta visão de segurança em seus atos, atitudes, e opiniões.

Nome

e-mail

Isto não significa que os outros não tenham uma visão de segurança adequada, mas apenas que os citados são os destaques naturais nesta característica, ou aqueles cujos nomes espontaneamente lhe vieram à mente.

- Considerando o seu dia a dia de trabalho, liste as pessoas a quem você costuma recorrer quando tem uma dúvida em assunto relacionado à segurança.

Nome e-mail

\section{(2) Abertura e comunicação}

Observe o IPEN e, em particular, a sua gerência no tocante à eficácia da comunicação com todos os empregados. Nosso foco é nas iniciativas de comunicação que geram um ambiente de confiança e abertura fazendo com que cada um se sinta seguro de estar de posse das informações 
necessárias para seu trabalho, sua segurança e sua carreira. Em sua opinião, quem são as pessoas que mais se destacam no quesito comunicação e abertura:

- Diretamente, pois são comunicadores natos, simpáticos e lúcidos ao expressarem suas idéias e mensagens.

Nome

e-mail

- Indiretamente, pois foram responsáveis por criar (ou aperfeiçoar) sistemáticas e canais de comunicação que muito facilitam tais atividades.

Nome

e-mail

Ao mencionar alguns, isto não significa que os outros não saibam se comunicar ou não contribuam para a boa comunicação, mas apenas que os citados são os destaques naturais nesta característica.

\section{(3) Colaboração e trabalho em equipe}

Trabalho em equipes, grupos de trabalho e times multifuncionais são experiências que praticamente todos já tivemos em nossa vida profissional. Há algumas pessoas que parecem ter nascido para este tipo de atividade, pois elas animam o grupo, são pró-ativas, gerenciam eventuais conflitos e conseguem com que todos dêem o melhor de si. São pessoas que trazem muita sinergia ao grupo que participam e, muitas vezes, não são as que têm maior bagagem de conhecimento, mas elas são como fermento e fazem com que a "trabalho do grupo" cresça e apareça.

- Em sua opinião, quem são os destaques os nesta característica no IPEN e, em particular, na sua gerência. 
- Liste também as pessoas com quem você teve alguma experiência de trabalho em equipe no último ano.

Nome

e-mail

\section{(4) Aprendizado organizacional}

Há pessoas que estão sempre aprendendo e aperfeiçoando suas capacidades, habilidades e facilidade no trabalho. Tais pessoas costumam transformar eventuais problemas em oportunidades de aprender, normalmente são também abertas ao diálogo e facilmente compartilham seus conhecimentos com os colegas, bem como aprendem com eles também.

Em sua opinião, quem são os destaques naturais nesta característica no IPEN e, em particular, na sua gerência.

Nome

e-mail 


\section{ANEXO C - QUESTIONÁRIO PARA LEVANTAMENTO DAS CRENÇAS}

Para cada um dos do questionário, por favor, leia a afirmativa com atenção e marque sua resposta indicando o quão fortemente você concorda ou discorda escolhendo a alternativa expressa sua opinião entre as seguintes:

_ Discordo fortemente;

_Discordo em parte;

- Não concordo nem discordo;

_ Concordo em parte;

_ Concordo fortemente.

1. A política de segurança e suas implicações nas atividades do meu Centro são conhecidas por todos.

Discordo fortemente;

_Discordo em parte;

_ Não concordo nem discordo;

_Concordo em parte;

_ Concordo fortemente;

2. As informações relevantes à segurança encontram-se registradas de vária formas, ou seja, manuais, relatórios, procedimentos, avisos etc e a maioria delas é disponível tanto por escrito como na intranet. Discordo fortemente;

Discordo em parte;

_ Não concordo nem discordo;

_Concordo em parte;

_ Concordo fortemente; 
3. A alocação de recursos (pessoas, equipamentos, orçamento etc) para as atividades relacionadas à segurança claramente reflete a grande importância que deve ser dada ao tema.

Discordo fortemente;

Discordo em parte;

Não concordo nem discordo;

Concordo em parte;

Concordo fortemente;

4. Em meu Centro, as pessoas sabem que segurança e operação devem andar juntas e isto é algo visível nas ações, opiniões e atitudes de todos.

Discordo fortemente;

Discordo em parte;

Não concordo nem discordo;

_Concordo em parte;

Concordo fortemente;

5. Segurança, em todos seus aspectos, é considerada no planejamento, é praticada na execução e usada na avaliação posterior de todas as atividades e projetos do meu Centro.

Discordo fortemente;

Discordo em parte;

Não concordo nem discordo;

Concordo em parte;

Concordo fortemente;

6. A liderança para as questões de segurança, tanto no discurso como na prática, emana da gerência e é delegada a todos os níveis necessários para tais questões nunca fiquem esquecidas.

Discordo fortemente;

Discordo em parte;

Não concordo nem discordo;

_Concordo em parte;

Concordo fortemente; 
7. Idéias e iniciativas no sentido de melhora a segurança são sempre recebidas com entusiasmo pela gerência e a participação dos funcionários neste sentido é realmente encorajada. Discordo fortemente;

Discordo em parte;

Não concordo nem discordo;

Concordo em parte;

Concordo fortemente;

8. Em meu Centro, todos se sentem responsáveis no sentido de informar e colaborar com os colegas quanto a observações que tenham feito e que podem ter implicações na segurança, mas por outro lado a cadeia de responsabilidades para as decisões e ações com impacto na segurança é muito claramente definida e explicitada.

Discordo fortemente;

_Discordo em parte;

_ Não concordo nem discordo;

_Concordo em parte;

Concordo fortemente;

9. Em meu Centro trabalho em equipe é algo que feito com muita naturalidade e eficiência, pois as pessoas têm uma cultura muito propícia para este tipo de atividade.

Discordo fortemente;

_Discordo em parte;

_ Não concordo nem discordo;

_Concordo em parte;

Concordo fortemente; 
10. Aprender com os colegas e ensinar também ,sempre que surge uma oportunidade, é algo muito valorizado, pois todos têm o claro entendimento que o Centro está ganhando muito com isto

_ Discordo fortemente;

_Discordo em parte;

_ Não concordo nem discordo;

_ Concordo em parte;

_ Concordo fortemente; 


\section{ANEXO D - FLUXO DO LEVANTAMENTO DE REDES}

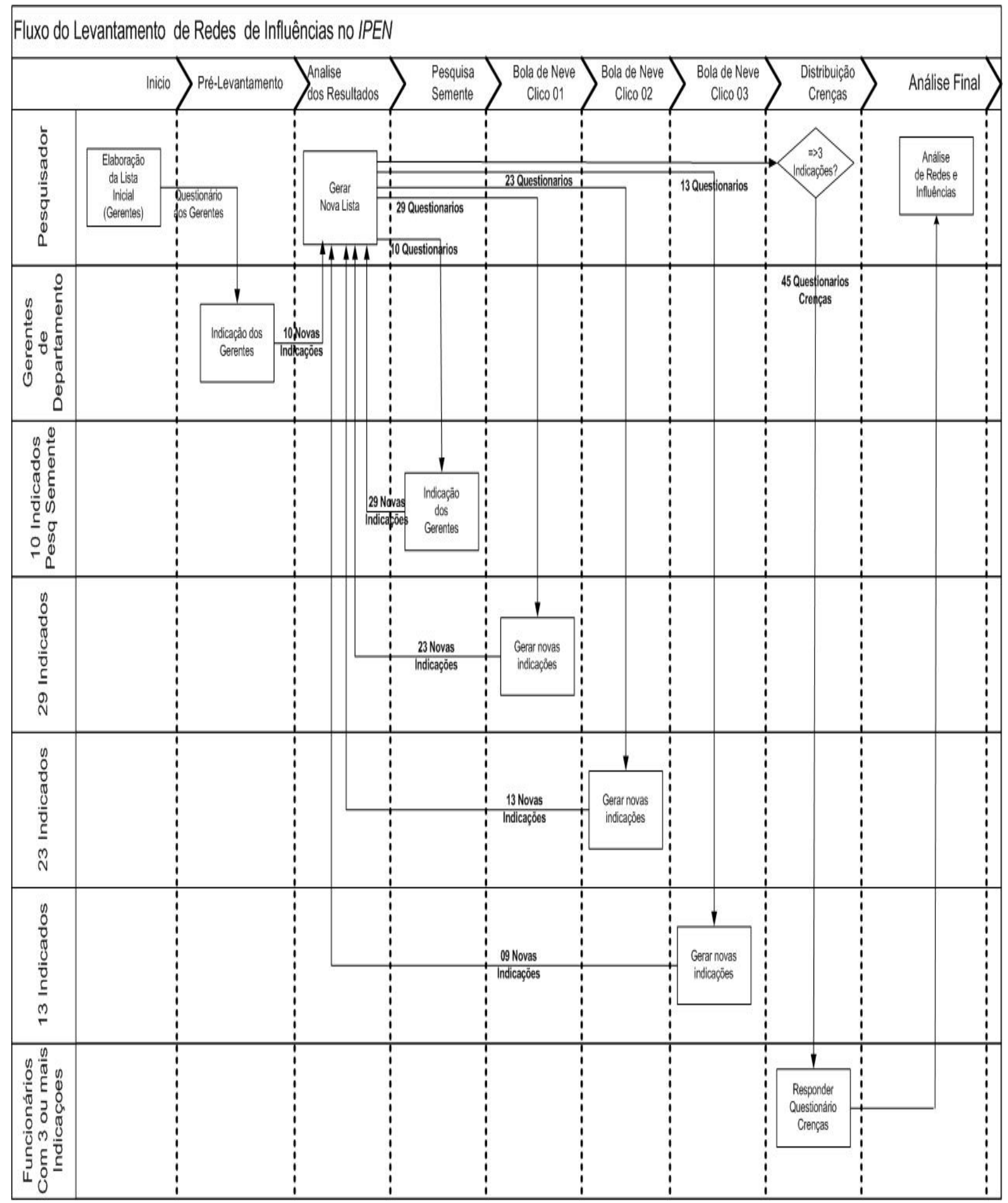

